\title{
ESTRUCTURA Y TEXTURA EN UN TEXTO TRADICIONAL BRIBRI
}

\author{
Carla Victoria Jara Murillo
}

\begin{abstract}
RESUMEN
En el presente artículo se analiza el texto "Mĩ kã Sibö tskìnẽ" (Cuando Sibö nació) de la tradición oral bribri, en dos aspectos: primero se establece su estructura con base en la partición del texto por sus continuidades de tópicos y acciones; en segundo término se analiza la propiedad de textura, entendida esta como el conjunto de mecanismos lingüísticos que le dan a un texto su carácter cohesivo. Se incluye como anexo el texto original completo, con traducción morfemática y versión al español.

Palabras clave: bribri, análisis textual, lenguas indígenas, tradición.
\end{abstract}

\begin{abstract}
In this paper the text "Mĩ̀nã Sibö tskìnẽ" (When Sibö was born) from the Bribri oral tradition is analyzed in two respects: first, its structure is established by partitioning the text on the basis of topic and action continuity; secondly, the property of texture is analyzed, understanding by texture a set of linguistic mechanisms which makes a text hang cohesively together. The complete original text is included with morphemic translation and Spanish version.

Key words: bribri, textual analysis, indigenous languages, oral tradition.
\end{abstract}

\section{Introducción}

El bribri es hablado por alrededor de 10.000 personas en el sureste de Costa Rica, a ambos lados de la Cordillera de Talamanca. Del lado pacífico de la cordillera, los bribris habitan en el cantón de Buenos Aires, provincia de Puntarenas, en las reservas de Salitre y Cabagra. En esta parte los bribris suman alrededor de 3000 personas. Del lado de la cordillera que desciende hacia la costa Atlántica, los bribris son cerca de 7000; habitan principalmente en la Reserva de Talamanca, que se encuentra en el cantón del mismo nombre, en la provincia de Limón. Se reconocen tres dialectos del bribri: Amubre, Salitre y Coroma (Jara Murillo 2004). La narración que se analiza en este artículo corresponde al bribri de Coroma.

Carla Victoria Jara Murillo. Profesora de la Escuela de Filología, Lingüística y Literatura. Universidad de Costa Rica, San Pedro, San José.

Correo electrónico: cjara@cariari.ucr.ac.cr, cvjara@yahoo.com 


\title{
2. Estructura del texto
}

\subsection{Preliminares}

Los niveles de organización del discurso propuestos por Longacre (1976) proveen un punto de partida útil para la segmentación de un texto en sus partes constituyentes. Para Longacre, el discurso se estructura en:

1. Ia cláusula, que es una "cadena predicacional" (predicational string);

2. la oración, que es "preeminentemente el nivel de combinación de las cláusulas";

3. el párrafo, que es "la unidad de desarrollo del discurso"; y

4. $\quad$ el discurso, como "el nivel del todo" (Longacre 1976: 273-276).

Givón, por su parte, se refiere a la estructura jerárquica del discurso del siguiente modo:

\begin{abstract}
El discurso multiproposicional no es simplemente una concatenación ('cadena') de proposiciones atómicas. Más bien, tiende a desplegar una estructura más elaborada y comúnmente jerárquica. Típicamente, con la narrativa sirviendo por el momento como el prototipo del discurso, la historia total se divide en capítulos, los capítulos en episodios, los episodios en macropárrafos y estos últimos en más pequeños párrafos temáticos. Estos se componen de oraciones complejas y/o, finalmente de proposiciones ('cláusulas'). Esta disposición jerárquica de las unidades es parte de la estructura temática del discurso (Givón 1984: 137).
\end{abstract}

Tanto Longacre como Givón reconocen así la estructura jerárquica del discurso: el discurso está compuesto por unidades lingüísticas que son analizables por sí mismas y están, al mismo tiempo, dispuestas de manera jerárquica dentro de cualquier pieza de discurso. La diferencia entre los dos autores es de perspectiva en el análisis. Mientras que Longacre parte de unidades más pequeñas hacia el nivel del discurso como un todo, el objetivo de Givón es el discurso multiproposicional, el cual permite la definición de unidades lingüísticas más específicas en términos de tópicos, esto es, las entidades particulares a las que hace referencia el lenguaje humano. En este trabajo, utilizaré la noción de tópico en este sentido givoniano: los tópicos del texto son las entidades sobre las cuales trata la historia, esto es, los personajes participantes.

La noción de niveles del discurso permite la segmentación de un texto en unidades textuales como las reconocidas por Longacre y Givón. En el anexo de este trabajo, se presenta el texto completo Mĩ kã Sibö tskĩ nẽ segmentado en los niveles de: mundos discursivos, escenas, párrafos, oraciones y cláusulas. Es importante destacar que en la presentación del texto que se hace en el anexo, las oraciones están articuladas mediante puntuación convencional, pero cada línea de texto (280 en total) corresponde a una sola cláusula. La barra inclinada hacia la derecha ( / ) al inicio de una línea de texto indica que la cláusula que sigue es subordinada de la anterior.

De acuerdo con Grimes (1975), existen tres clases generales de unidades semánticas:

1. relaciones de caso: una clase de predicados típicamente dominados y seleccionados por predicados léxicos;

2. predicados léxicos: el significado de las palabras;

3. predicados retóricos: predicados que unen proposiciones compuestas de predicados léxicos y casos para formar complejos retóricos. 
De acuerdo con Grimes, entonces, la cláusula se define como la expresión mínima de predicados léxicos y casos (Ibíd:: 108), mientras que la expresión mínima de los predicados retóricos es más amplia que la cláusula y a menudo implica la oración. En el texto analizado estos complejos retóricos se marcan linguiísticamente mediante elementos conjuntivos que relacionan cláusulas.

Por su parte, Givón(1990) describe la cláusula así:

\begin{abstract}
Algo como una proposición mental (...) es la unidad básica del almacenamiento mental de información. Cuando se codifica como cláusula en la comunicación real, la proposición mental solo débilmente se parece a la proposición aristotélica en toda su dimensión, o a su equivalente chomskyana, la estructura profunda de la oración. En el discurso oral interconectado, la proposición mental a menudo aparece como una cláusula trunca, puede carecer de su verbo/predicado, aunque esto es menos común. Más a menudo, la forma de superficie carece del sujeto y/o del objeto directo, aunque estos son mentalmente recuperables. (...) Pero cualquiera que sea la forma que tengan en la superficie, las proposiciones mentales codifican algún estado o evento, y han sido reconocidas como las unidades básicas del procesamiento del discurso (Givón 1990: 896).
\end{abstract}

Desde un punto de vista teórico, la cláusula es el nivel de codificación gramatical en el cual se asignan las categorías de orden de palabras y caso. Por ejemplo, en la lengua bribri la estructura básica de la cláusula es "ABS(olutivo) + VERBO” (cf. Jara: 1995b) con ordenamiento rígido y esta estructura es la recurrente en el discurso.

Pero vemos que la cláusula no constituye la unidad real de comunicación. Para poder funcionar en la comunicación, la cláusula requiere la asignación de un modo por parte del hablante; el modo se manifiesta gramaticalmente y es a partir de entonces que se convierte en una oración. Tampoco reside la cláusula en el nivel de la representación semántica, en donde no existen los casos gramaticales ni el orden de palabras. El nivel de la cláusula se localiza entre la proposición mental (en la mente de los hablantes) y la oración (en la comunicación real).

Ahora, tal como afirman Halliday \& Hasan (1976: 8), "la oración es una unidad significativa para la cohesión porque siendo la mayor unidad de la estructura gramatical, determina la manera en que se expresa la cohesión”. La manera en que funciona la cohesión al interior de las oraciones puede ilustrarse mediante el siguiente ejemplo: Dadas dos proposiciones tales como

(1a) construir $\left(\mathrm{Juan}_{1}-\mathrm{AG}, \mathrm{casas}_{1}-\mathrm{PAC}\right), \mathrm{y}$

(1b) vender (Juan 1 -AG, casas $_{1}$-PAC),

estas pueden codificarse en cláusulas tales como:

(2a) Juan-SUJ / construye / casas-OBJDIR, y

(2b) Juan-SUJ / vende / casas-OBJDIR,

en donde el orden de palabras y los casos gramaticales de sujeto y objeto directo han sido asignados. En la comunicación real, sin embargo, estas cláusulas se codifican en oraciones que manifiestan cohesión tales como:

3) Juan construye casas y las vende

Primero que nada, se ha asignado el modo declarativo; en segundo lugar, el recurso cohesivo de la conjunción ha convertido las dos cláusulas en una oración compuesta mediante 
el uso de la conjunción y, manifestando así estructura retórica, según la concibe Grimes (op. cit.). Pero lo más importante para la cohesión son las ligas cohesivas que se dan entre las dos cláusulas (discutiré en detalle el concepto de liga cohesiva en el siguiente apartado):

$$
\begin{array}{cc}
\text {Juan}_{1} \text { construye } \text { casas }_{1} \text { y } \\
\downarrow & \downarrow \\
0_{1} & \text { las }_{1} \text { vende. }
\end{array}
$$

Por virtud de la continuidad referencial, en la segunda cláusula el sujeto-agente queda sin expresarse (anáfora cero) y un pronombre anafórico sustituye al objeto-paciente. Como menciona Givón en el párrafo anteriormente citado, algunas veces se prescinde de la mención explícita de los argumentos, ya que son recuperables del contexto, como muestra el siguiente ejemplo de texto bribri que aquí se analiza (líneas 133-135 en el anexo):

$$
\begin{aligned}
& 0 \text { Bikili' kölö̀wếwa, } \quad 00 \text { wö̀té, } \quad 00 \text { péumĩ. } \\
& \text { 3P zorro agarrar.PER picar.PER botar.PER }
\end{aligned}
$$

'Agarraron al zorro, lo picaron y lo botaron'.

En resumen, las oraciones se definen aquí como la codificación gramatical de una o más cláusulas a las cuales el hablante ha asignado un valor modal.

Los párrafos son porciones de discurso que pueden definirse por continuidad del tópico, pero también por continuidad de la acción y/o por continuidad del escenario. Un cambio de tópico, de acción, y/o de escenario puede marcar lindes entre párrafos. Un párrafo definido por continuidad del tópico se refiere al mismo participante o conjunto de participantes. Sin embargo, muchos párrafos sucesivos pueden referirse al mismo participante; en otras palabras, la continuidad del tópico puede manifestarse a lo largo de muchos párrafos. En este caso, los lindes entre párrafos pueden estar marcados por un cambio en la acción o un cambio en el escenario espacial o temporal.

La agrupación de varios párrafos puede representar otros niveles de discurso tales como episodios, capítulos, etc. En este análisis, he utilizado el término de escenas para referirme a la misma subunidad discursiva denominada por Grimes episodio: "En relación con la unidad de reparto [de personajes], un episodio puede consistir de una serie de párrafos en los cuales los mismos personajes intervienen, de manera que un nuevo episodio comienza cuando se da un cambio significativo de participantes" (Ibíd::110).

Grimes también sugiere, siguiendo a Gleason (1968), que una partición preliminar del texto se puede hacer sobre la base de la premisa de que diferentes partes del discurso transmiten diferentes clases de información. La primera distinción por hacer en cuanto a las clases de información que se codifican en las cláusulas es, por una parte, la información referida a predicados y casos (eventos y los participantes involucrados en ellos: qué le sucedió a quién, quién hizo qué a quién, etc.), y por otra, las demás clases de información. Estas otras clases de información incluyen: escenario (dónde, cuándo, en qué circunstancias), información antecedente o explicativa, evaluaciones del hablante e información colateral (qué no sucedió o no ha sucedido todavía). Por ejemplo, en el párrafo 12 del texto analizado, el narrador introduce información explicativa que se refiere a un evento externo a la línea principal de la acción pero relacionado con ella. Esta inserción muestra ser un párrafo en 
sí mismo, mostrando su propia estructura interna, sus participantes, eventos y escenario particulares a esa porción de discurso.

De acuerdo con Grimes, un texto puede ser segmentado sobre varias distintas bases:

1. Sobre la base del escenario espacial y/o temporal, en donde un cambio en el escenario físico o el tiempo indica una nueva unidad textual.

2. Sobre la base del tema: "Mientras el hablante continúe hablando de la misma cosa, se mantiene dentro de un solo segmento del texto en algún nivel de la segmentación" (Ibíd.: 103). Cuando el tema cambia, se marca un linde entre dos unidades textuales. Algunas lenguas tienen una organización temática que incluye al menos un tema global para el discurso total y temas locales que cubren secciones del discurso definiendo así segmentos de discurso. Se verá a lo largo del análisis que la organización temática permite reconocer las diferentes unidades de discurso que componen el texto bribri.

3. Uniformidad del reparto de personajes: Un reparto de personajes es un grupo que puede variar en su composición y sin embargo seguir funcionando como el mismo grupo para efectos de referencia lingüística. Un cambio relevante de los participantes puede indicar un cambio de unidad textual.

4. Orientación de los participantes: "Existen segmentos durante los cuales un solo participante mantiene un nivel relativamente alto de actividad en relación con los demás participantes. Cada segmento tiene una orientación uniforme hacia las acciones dentro del párrafo (Ibíd.: 104).

Lo que Grimes define como orientación de los participantes corresponde al concepto de continuidad del tópico de Givón. Sobre la base de orientación común, "una secuencia de eventos se distingue de una sección posterior de la misma secuencia temporal por el hecho de que todas las acciones en cada sección implican relaciones uniformes entre sus participantes" (loc. cit.). En este trabajo se verá que la partición de un texto puede hacerse de acuerdo con una o más de estas bases; la partición del texto analizado se basa en la continuidad de las entidades tópicas, el reparto de personajes y la organización temática.

\subsection{El cambio de tópico como marcador de linde}

La continuidad del tópico claramente divide el texto Mĩkã Sibötskìnẽ en dos mundos discursivos a los cuales he llamado el Mundo de Siböy el Mundo de Tsökölpa ‘cantores'. El cambio en la continuidad del tópico marca el cambio de un mundo a otro. Estas dos partes principales del texto no pueden considerarse géneros independientes, a pesar de constituir diferentes tipos de discurso: el Mundo de Sibö está constituido básicamente por discurso narrativo, mientras que el Mundo de Tsókölpa está constituido básicamente por discurso descriptivo. Esta organización temática, en la que el narrador comienza el discurso con alguna historia relacionada con el dios Siböy luego continúa con la descripción de las ceremonias rituales es típica de la tradición oral bribri que se refiere a su historia / mitología / religión, colección de tradiciones orales llamada sũwố, palabra que puede significar según el contexto 'historia', 'viento' o 'alma' (cp. Borge et al. 1994, Jara 1995). Hay una relación causal entre ambos mundos: el primero motiva el segundo. El Mundo de Sibö le da su razón de ser al Mundo de Tsókölpa, que guarda una relación metonímica con el mundo real, actual, de los bribris. El cambio en el tipo de discurso, así como el cambio de tópico, claramente delimita los dos mundos. 
La Tabla 1. Mundos discursivos en el texto Mĩ̀kã Sibötskìñ̃ muestra la ubicación de cada mundo en relación con el texto completo, las escenas contenidas en cada uno y el reparto de personajes involucrado en cada escena.

Tabla 1. Mundos discursivos en el texto Mĩ̀kã Sibö tskìñ

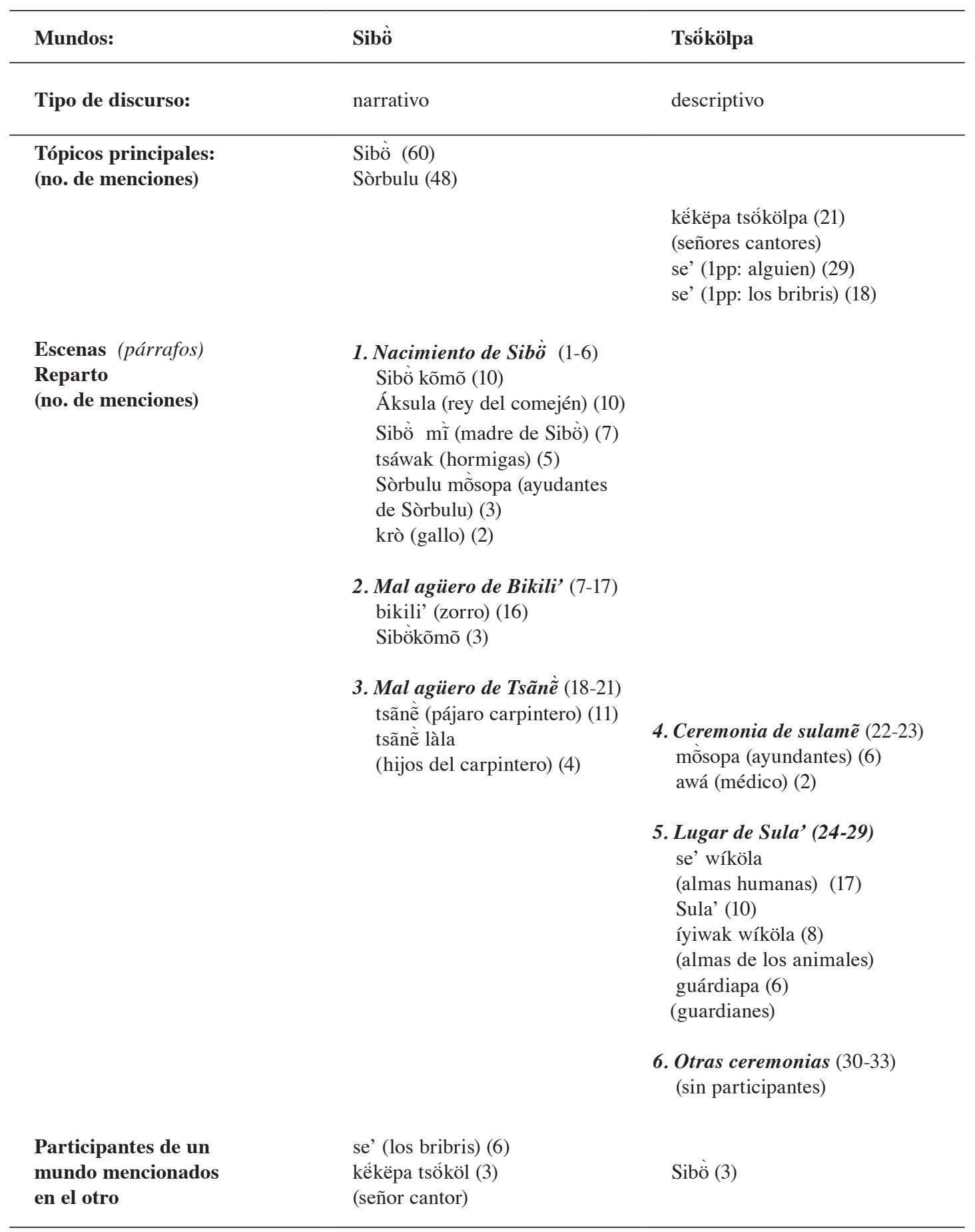




\subsection{Partición del texto}

De acuerdo con la Tabla 1, vemos que la narración ha sido segmentada en mundos discursivos con base en los tópicos principales y estos en escenas, con base en los repartos de participantes, de la siguiente manera:

\section{Mundo de Sibö:}

Escena 1: El nacimiento de Sibö (párrafos 1-6)

Escena 2: El mal agüero de bikilí (párrafos 7-17)

Escena 3: El mal agüero de tsãnè (párrafos 18-21)

\section{Mundo de Tsốkölpa:}

Escena 4: La ceremonia de sulàmẽ (párrafos 22-23)

Escena 5: El lugar de Sula' (párrafos 24-29)

Escena 6: Otras ceremonias (párrafos 30-33)

El texto puede además dividirse en párrafos temáticos. La Escena 1 ha sido analizada en otro trabajo (Jara 2003), atendiendo en particular a la codificación de los participantes. Ahí se establecieron los siguientes párrafos temáticos:

\section{Escena 1: El nacimiento de Sibö (párrafos 1-6)}

1. Resumen introductorio: Este primer párrafo tiene la función de introducir a los participantes tópicos o continuos, los principales eventos de la narración y las circunstancias de tiempo y espacio.

2. Ubicación espacial y señal del nacimiento: La función de este párrafo es introducir el escenario de las acciones de la escena, en particular, el canto del gallo, que constituye la señal del nacimiento de Sibö.

3. Presentación de los Sòrbulu: Se caracteriza por la topicalización del personaje antágonico al dios Sibö, Sòrbulu. Cabe aclarar que en la narrativa bribri, Sòrbulu es el eterno enemigo de Siböy aparece como personaje individual y colectivo.

4. Identificación de la señal y plan de acción: Se caracteriza por codificar información colateral, esto es, la que se refiere a eventos que no han sucedido. En la narrativa bribri este tipo de información suele aparecer en el discurso citado de los participantes. Aunque se considera el discurso citado de los participantes principalmente como información colateral (cp. Grimes op. cit.), debe notarse que este puede también introducir información acerca de los eventos principales de la historia. En la narrativa bribri, el diálogo citado de los personajes sirve la función principal de vivificar y 
actualizar los eventos de la línea principal de acción; sin embargo no es indispensable en la narración, hecho que apoyaría su caracterización como información colateral. Es probable que constituyera una parte más estructural de la narrativa en épocas anteriores, ya que es en las historias de los mayores donde más se presenta el discurso citado, mientras que en las narraciones de los más jóvenes suele estar ausente.

5. Solicitud de Sibömĩ̀y respuesta de Áksula: Básicamente está constituido por la interacción directamente citada de dos participantes que a su vez funcionan como tópicos del párrafo.

6. Colaboración de tsáwak: Finalmente, Siböestará a salvo gracias a la intervención del participante colectivo tsáwak, que constituye el tópico de este último párrafo.

En el anexo se observará que el texto ha sido segmentado en 33 párrafos; no haré el análisis detallado de todos ellos; me limitaré a presentar aquí el análisis de los párrafos de la Escena 2.

\section{Escena 2: El mal agüero de bikili' (párrafos 7-17)}

7. Interacción entre Sibö y su padre Sibökõmõ: Sibö aparece como tópico del párrafo, con 11 menciones, frente a 3 de su interlocutor en la secuencia, su padre Sibökõmõ, y 3 menciones del participante Sòrbulu. La unidad del párrafo también está determinada por una única circunstancia temporal: cuando Sibö se hizo hombre, y una acción unitaria: el diálogo entre Sibò̀ y su padre.

8. Siböviene al lugar de Sòrbulu. Sibö sigue siendo tópico, mientras que el linde con el párrafo anterior se señaliza mediante cambio de acción y de ubicación espacial.

9. Los Sòrbulu en su lugar. Con respecto al párrafo anterior, el linde se marca mediante cambio de tópico, con el cual se introduce en la escena al participante Sòrbulu. Durante el desarrollo de este párrafo, todas las acciones son realizadas por este participante. Se introduce el participante bikili' (zorro), pero debido a que está todavía inerte y no realiza ninguna acción, el párrafo sigue siendo caracterizado por el tópico Sòrbulu.

10. El mal agüero. Este párrafo tiene una nueva unidad de acción basada en la interacción entre Sibö y Sòrbulu. El linde entre párrafos está explícitamente marcado mediante el adverbial iñ̃ 'hoy'; en el contexto de la narrativa, este elemento introduce una nueva acción que es llevada a cabo por un participante diferente que ahora se convierte en tópico.

11. Sibö y bikili’. Siböes reinsertado como tópico y se reintroduce el participante bikili’ en la escena. 
12. El canto que Sibö dejó para pelear contra los téribes. Ya habíamos mencionado este párrafo, al discutir los distintos tipos de información que se codifican en el discurso. Aquí el cambio de tópico nos transporta al mundo de los cantores. $\mathrm{Sa}$ ' 'nosotros los bribris' se tematiza en posición inicial y se introduce un canto y otra información de segundo plano.

13. Bikili' cobra vida. De nuevo el cambio de tópico marca linde entre este y el párrafo anterior. El tópico bikili’, el zorro, recobra vitalidad al ser soplado por Sibö. La unidad de la acción está constituida por la interacción entre Siböy bikili’.

14. Canto de ceremonia fúnebre para niños. El inicio del párrafo está marcado por una circunstancia temporal retrospectiva (línea 111: Esto era antes). El párrafo está compuesto por información de segundo plano, y al igual que el párrafo 12, se transporta al mundo de los cantores. Aquí $s a$ ' 'nosotros los bribris' se tematiza en la línea 112 y se introduce un canto fúnebre para niños.

15. Continuación de la acción del párrafo 13 entre bikili’ y Sibö. Se retorna a los tópicos bikili’ y Sibö. La continuidad de la acción está dada por su interacción.

16. Los Sòrbulu atacan a Sibö. El linde está marcado mediante la partícula ñè̃e 'entonces'. Sòrbulu constituye el tópico del párrafo y la unidad de acción está dada por la interacción entre Sòrbulu y Sibö.

17. Fin de la escena y conclusión: por qué el zorro no se puede comer. Sòrbulu, con 10 menciones, continúa como tópico principal y bikili es el tópico secundario (8 menciones).

Con esta segmentación de la escena, hemos visto que la topicalidad de los participantes y los cambios en la continuidad de acción, tiempo y/o espacio permiten marcar lindes entre unidades discursivas intermedias: los párrafos. En el anexo puede verse la partición del texto completo en párrafos temáticos; aquí se ha querido mostrar cómo la topicalidad de los participantes y la unidad de acción interactúan en la organización temática del texto en unidades discursivas intermedias. En el siguiente apartado se verán estrategias particulares de cohesión que se utilizan a lo largo del texto.

\section{La función textual en la lingüística funcionalista de M.A.K. Halliday}

\subsection{Preliminares}

M.A.K. Halliday (1967, 1968), siguiendo a Firth (1935), se propuso construir una teoría funcional del texto con base en la siguiente premisa: los textos no son un nivel de descripción gramatical sino una forma de uso del lenguaje. Su interés era estudiar el funcionamiento del texto en el contexto de la situación y en el contexto de la cultura, conceptos que toma de Malinowski (1923, 1935). Más adelante, Halliday \& Hasan (1989) desarrollan una teoría del análisis textual basada en las nociones de función y contexto de la situación. 
En este marco, "el concepto de función es sinónimo del concepto de uso" (Halliday \& Hasan 1989: 17). Halliday define el texto como "cualquier instancia de lenguaje vivo que desempeñe algún papel en un contexto de situación” (Ibíd.: 10). Un texto es una unidad semántica codificada en palabras y estructuras, las cuales a su vez son recodificadas en sonidos (o símbolos gráficos). Como señala Halliday, "tiene que estar codificado en algo para que pueda ser comunicado, pero como cosa en sí misma, un texto es esencialmente una unidad semántica" (loc. cit). Desde esta perspectiva social-semiótica del análisis textual, un texto se considera una forma de intercambio de significados creada por el sistema social:

Ahora, el contexto de la situación -el contexto en el que se desenvuelve el texto- está encapsulado en
el texto... mediante una relación sistemática con el ambiente social, por una parte, y con la organización
funcional del lenguaje, por otra. Si tratamos tanto al texto como al contexto como fenómenos semióticos,
como 'modos de significar', por así decirlo, podemos pasar de uno a otro de manera reveladora (Ibid.: 11).

Halliday ha propuesto que tres componentes del contexto deben describirse para cada texto particular: el campo (field), el tenor (tenor) y el modo (mode) del discurso, y define estos componentes así:

1. El campo del discurso se refiere a lo que está sucediendo, a la naturaleza de la acción social que está teniendo lugar; responde a la pregunta: ¿en qué es que los participantes están involucrados?

2. El tenor del discurso se refiere a la naturaleza de los participantes y sus roles; responde a la pregunta: ¿qué clase de relación se da entre los participantes?

3. El modo del discurso se refiere al papel que desempeña el lenguaje, la organización simbólica del texto, el estatus que tiene y su función en el contexto; responde a la pregunta: ¿qué es lo que los participantes esperan que el lenguaje haga para ellos en la situación dada? (Ibíd:: 14).

Correspondiendo a cada uno de estos componentes del contexto de situación, Halliday propone las siguientes funciones del lenguaje:

1. Función ideacional: "El lenguaje sirve para la expresión de contenido semántico". La función experiencial corresponde a la "representación de algún fenómeno en el mundo real" (Halliday \& Hasan 1989: 19). Esto se refiere al contenido proposicional del texto: el estado o evento y los participantes y circunstancias relacionadas con ese estado o evento, codificados en las cláusulas del texto. El significado experiencial junto con el significado lógico (las relaciones semánticas entre las cláusulas del texto) corresponden a la función ideacional del lenguaje.

2. Función interpersonal: "El lenguaje sirve para establecer y mantener relaciones sociales". La función interpersonal conlleva significado interpersonal, es decir, el lenguaje funciona como un medio en el proceso de interacción social. Halliday relaciona el significado experiencial y el significado interpersonal del siguiente modo: 
La oración no es solamente representación de la realidad; es también una pieza de interacción entre hablante y oyente. Mientras que en su significado experiencial el lenguaje es una manera de reflejar, en su significado interpersonal el lenguaje es una manera de actuar; podemos (...) hablar de LENGUAJE COMO REFLEXIÓN y de LENGUAJE COMO ACCIÓN como un modo alternativo de referirnos al significado experiencial y al significado interpersonal (Ibíd.: 20).

3. Función textual: "El lenguaje tiene mecanismos para establecer vínculos dentro de sí mismo y con los rasgos de la situación en la que es utilizado por los hablantes".

En este artículo me concentraré en el significado que corresponde a la tercera dimensión del contexto, el modo. Según señala Halliday, “el modo, esto es, el papel particular que el lenguaje desempeña en el evento (...), se refleja en lo que hemos llamado el significado textual, que incluye los patrones cohesivos" (Ibíd.: 28).

El campo, el tenor y el modo tienen expresiones concretas en el texto. El campo se refleja en el vocabulario, en la denominación de los procesos y los participantes, es decir, en las estructuras gramaticales de la transitividad. Las cláusulas son las unidades básicas para codificar los rasgos del campo.

El tenor se refleja mediante la elección de persona y de función de habla (afirmación, solicitud, mandato, etc.), que se realizan gramaticalmente por medio de los diferentes modos gramaticales: declarativo, interrogativo, imperativo, etc. Las oraciones -que se componen de cláusula(s) y modo gramatical- son las unidades básicas en las que se codifican los rasgos del tenor.

El modo del discurso se refleja en la estructura y en las relaciones de cohesión internas al texto, las cuales constituyen la propiedad de textura. La estructura se define como el conjunto de elementos o partes que componen el texto, lo cual hemos desarrollado en la sección anterior. En esta intentaré ejemplificar la textura tal como se manifiesta en la narración Mìkã Sibötskìne.

\subsection{Estructura y textura}

La textura se define como el conjunto de relaciones semánticas que dan continuidad a un texto. Es la existencia de textura lo que hace que un texto sea interpretable.

\footnotetext{
Textura es el término técnico utilizado para referirse al hecho de que las unidades lexicogramaticales que codifican un texto se hallan vinculadas -que existe cohesión lingüística dentro de un pasaje. Esta cohesión es producida por el uso de recursos lingüísticos tales como referencia, sustitución, elipsis, conjunción y organización léxica (Hasan 1978: 228).
}

Halliday \& Hasan (1989: 72) hacen las siguientes observaciones con respecto a la textura:

1. La textura se manifiesta mediante ciertas clases de relaciones semánticas entre los mensajes individuales del texto.

2. La textura y la estructura son independientes, es decir, un texto puede tener textura y al mismo tiempo carecer de ciertos componentes estructurales, por lo que resulta en un texto incompleto, desde el punto de vista del género al que pertenece. Esto supone una relación de una sola vía entre textura y estructura: "cualquier cosa que sea parte de un texto debe tener textura; puede ser o no un texto (o parte del texto) completo" (loc. cit.). 
3. "La propiedad de textura se relaciona con la percepción de coherencia por parte del oyente" (loc. cit.). Debe notarse que la cohesión es una propiedad que el hablante construye en el desarrollo del texto, mientras que la coherencia se refiere a la percepción del texto como interpretable por parte del oyente. Discutiré más abajo la noción de coherencia.

La propiedad de textura se expresa mediante relaciones de significado dentro de un texto. La relación entre dos ítemes en un texto se denomina liga cohesiva (cohesive tie): "El concepto de liga hace posible analizar un texto en términos de sus propiedades cohesivas, y dar cuenta sistemática de sus patrones de textura" (Halliday \& Hasan 1976: 4). Una liga cohesiva implica una relación semántica entre dos elementos: "Los dos términos de una liga se unen por medio de alguna relación de significado. Tales relaciones semánticas forman la base de la cohesión entre los mensajes de un texto (Halliday \& Hasan 1989: 73).

Al establecer los distintos tipos de cohesión que se encuentran en los textos, una primera distinción por hacer es entre cohesión estructural y cohesión no estructural. La cohesión no estructural se codifica por medio de recursos gramaticales y léxicos. Hasan establece las siguientes posibles relaciones semántico-cohesivas en un texto:

1. Correferencialidad: una relación de identidad situacional de referencia. Los dos ítemes de la liga se refieren al mismo objeto en la realidad extralingüística: Llamé a María anoche y Juan también la llamó.

2. Coclasificación: los ítemes de la liga se refieren a objetos, procesos o circunstancias diferentes pero que pertenecen a la misma clase: Yo tengo el libro rojo y Juan el 0 azul.

3. Coextensión: los dos ítemes de la liga se refieren a conceptos que pertenecen al mismo campo semántico general: Prefiero tomar cerveza que vino.

Estos tres tipos generales de relaciones semánticas se codifican en un texto por medio de diversos recursos gramaticales. Típicamente, la correferencia se indica mediante recursos tales como los pronombres (Iba a llamar a María pero ella me llamó primero), artículos definidos (Iba a llamar a María pero la precisada me llamó primero), demostrativos (Iba a llamar a María pero esta me llamó primero), etc.

La coclasificación se codifica típicamente por medio de sustitución (Yo llamé a María y Juan también lo hizo) y elipsis (Yo llamé a María y Juan también 0).

En cuanto a la interpretación de estos recursos de codificación, hay una significativa diferencia entre el primer y el segundo miembro de una liga cohesiva. Un miembro de la liga se interpreta necesariamente por referencia al otro. En otras palabras, se puede interpretar el miembro A sin hacer referencia a ningún otro ítem del texto (es decir, el miembro A representa un recurso de codificación explícito), mientras que el miembro B (recurso de codificación implícito) debe ser interpretado en referencia a alguna fuente diferente a él, es decir, en referencia al miembro A. Como señala Hasan:

[Los recursos de codificación implícitos] se convierten en cohesivos -tienen una función cohesiva y por tanto son constitutivos del texto- precisamente si y cuando pueden ser interpretados a través de su relación con otro recurso de codificación (explícito) en el mismo pasaje (...). El establecimiento de tal liga crea cohesión (...). Tales recursos cohesivos han sido llamados RECURSOS COHESIVOS GRAMATICALES (Ibíd.: 75). 
Para interpretar un recurso implícito, se deben distinguir dos clases de ambiente del texto: 1) el ambiente extralingüístico o "contexto", relevante para el texto en su totalidad, y 2) el ambiente lingüístico o "cotexto", que es el lenguaje que rodea a las unidades linguísticas en cuestión. De acuerdo con esto, la fuente para interpretar un recurso implícito puede ser endofórica, cuando la fuente de interpretación se encuentra dentro del texto, es decir, en el cotexto; o puede ser exofórica cuando la fuente de interpretación está fuera del texto, es decir, en el contexto extralingüístico.

La referencia exofórica pertenece al dominio de la coherencia, esto es, a la percepción, por parte del oyente, del texto como interpretable. Este hecho se relaciona con la discusión de Clark (1977: 411) sobre inferencias tales como aquellas que "el hablante espera que el oyente tome como parte integral del mensaje". De acuerdo con Clark, mediante el proceso de "tendido de puentes" (bridging), los hablantes son capaces de reconocer los referentes a los que el hablante alude: "el oyente debe (...) establecer un puente entre lo que conoce y el pretendido antecedente" (Ibíd.: 413). Brown \& Yule (1993: 314) llaman a este tipo de inferencia presunción puente).

En resumen, la referencia exofórica o, para usar el término de Clark, el "tendido de puentes", no pertenece al dominio de la cohesión textual.

Ya que el lenguaje se desarrolla en el tiempo, las unidades lingüísticas ocurren en sucesión. Esto permite dos locaciones alternativas para un recurso de codificación endofórico: este puede aparecer después de su referente lingüístico (el miembro explícito de la liga); en este caso la referencia es anafórica (Yo llamé a María y Juan también la llamó). Alternativamente, el recurso de codificación endofórico puede aparecer antes que su referente lingüístico, en cuyo caso la referencia es catafórica (Cuando lo vi, supe que Juan estaba enfermo).

La noción de liga cohesiva textual se aplica solamente cuando la fuente para interpretar un recurso de codificación implícito es endofórica (anafórica o catafórica); cuando la fuente de interpretación es exofórica (es decir, cuando está fuera del texto) no hay cohesión textual, como ya se dijo, sino referencia al contexto extralingüístico o deixis. Me ocuparé de la cohesión textual en el análisis del texto Cuando Sibö Nació.

En resumen, la cohesión correferencial típicamente se codifica mediante recursos de referencia y la cohesión coclasificacional se codifica típicamente mediante sustitución y elipsis. La coextensión, por su parte, usualmente se codifica por medio de recursos léxicos. En la coextensión, ninguno de los elementos es implícito: ambos términos son típicamente "palabras de contenido" o "ítemes léxicos".

Por otra parte, un conjunto de recursos de cohesión no estructural, a los que Hasan llama orgánicos (Ibíd.: 81), son relaciones entre mensajes completos y se codifican básicamente de tres maneras: 1) por medio de partículas conjuntivas, como $y$, pero, porque, etc.; 2) mediante pares adyacentes como pregunta-respuesta, solicitud-acatamiento, etc., y 3) mediante partículas continuativas o de progresión, como así, entonces, etc. Las partículas conjuntivas y los pares adyacentes son recursos gramaticales, mientras que las partículas de progresión son recursos léxicos. En el texto se verá que la forma cha icha funciona a lo largo del discurso exclusivamente como partícula de progresión del discurso; mientras que los elementos conjuntivos, menos frecuentes, señalan la relación entre cláusulas que conforman complejos retóricos, según el término de Grimes comentado arriba.

Los recursos gramaticales y léxicos trabajan conjuntamente y se complementan en la conformación de la cohesión textual. Como señala Hasan, la cohesión gramatical y la léxica se 
mueven de la mano y al mismo tiempo a través de porciones de texto de longitud variable. Esto conduce al establecimiento de hilos de continuidad, los cuales se dan al unir varias ligas cohesivas con el mismo referente. Hasan define estos hilos de continuidad o cadenas cohesivas como "cadenas formadas por un conjunto de ítemes cada uno de los cuales se relaciona con los otros mediante las relaciones semánticas de correferencia, coclasificación y/o coextensión" (Ibíd:: 83).

Es posible, entonces, reconocer dos clases de cadenas cohesivas: 1) cadenas de identidad, que se forman por correferencia, y 2) cadenas de similitud, que se forman mediante coclasificación y/o coextensión. Las cadenas cohesivas constituyen un concepto básico para determinar la estructura de un texto como compuesto por distintos tipos de discurso: cada uno de ellos presumiblemente despliega sus propias cadenas cohesivas.

Las relaciones semánticas/cohesivas que hemos discutido hastaaquíson no estructurales porque implican relaciones entre unidades individuales del texto, independientemente de la existencia de estructuras mayores. Por otra parte, la cohesión estructural implica relaciones entre estructuras sintácticas o textuales mayores y presenta sus propios recursos de codificación. En este análisis se observarán dos clases de cohesión estructural: el paralelismo y la estructura temática.

El paralelismo implica una serie de estructuras paralelas (cláusulas o unidades mayores) que comparten ciertos rasgos y difieren en otros. Tal como Jakobson (1968) sugiere, el paralelismo, como otros recursos gramaticales utilizados en el arte verbal -por ejemplo, la organización estrófica-, evidencia la concepción del hablante acerca de equivalencias gramaticales y permite construir unidades dentro de los textos, basadas en correspondencias y similitudes.

La repetición de unidades mayores que la palabra también puede considerarse un tipo de paralelismo, con su propia función pragmática, como sugiere Brody (1986) en su análisis del discurso tojolabal, donde afirma, "para todos los tipos de repetición, es claro que decir la misma cosa otra vez no es de lo que se trata” (1986: 255). En el marco de la cohesión, la repetición puede funcionar como una estrategia para vincular oraciones, párrafos e incluso unidades textuales mayores. Según Brody (Ibíd:: 257), "la repetición puede servir también la función de cohesión mediante la contribución al establecimiento de un marco para el discurso dándole a este unidad formal, la cual ayudará tanto al hablante como al oyente a monitorear el discurso.

Esto se podrá apreciar en el texto que aquí se analiza, en donde el paralelismo y la repetición son utilizados en abundancia manifestando cohesión particularmente en el nivel de los párrafos.

La estructura temática es parte del sistema de cohesión de un texto, y se refiere a cómo los diferentes elementos se organizan entre sí en el desenvolvimiento general del discurso. Opera en varios niveles: cláusulas, párrafos y texto en su conjunto. La estructura temática puede proporcionar un medio para segmentar un texto en párrafos; un cambio de tema usualmente marca lindes entre párrafos, como vimos en la sección anterior. Como funciona a varios niveles, la estructura temática permite establecer cómo los párrafos se organizan en escenas (todos los párrafos en secuencia que tratan sobre el mismo tema) y las escenas en mundos (todas las escenas que tratan sobre los mismo temas). En la partición del texto, vimos que los dos mundos discursivos propuestos son cohesivos internamente por los hilos de continuidad que se establecen con base en las entidades tópicas de cada uno: Sibö̀ y los personajes con los 
que convive en su mundo, por una parte, y las actividades propias de los cantores en relación con el pueblo bribri, por otra.

Hasta aquí hemos comentado los siguientes recursos de cohesión:

\section{Recursos cohesivos no estructurales}

1. Referencia (recurso por identidad entre ítemes)

2. Sustitución (recurso por similitud entre ítemes)

3. Elipsis (recurso por similitud entre ítemes)

4. Conjunciones (recurso orgánico)

5. Pares adyacentes (recurso orgánico)

6. Partículas continuativas/de progresión (recurso orgánico)

\section{Recursos cohesivos estructurales}

1. Paralelismos

2. Repeticiones

3. Estructura temática

En el análisis de la historia bribri Mĩ̀nã Sibö tskinẽe, se mostrará cómo las más importantes estrategias de cohesión trabajan dentro de los distintos tipos de discurso que convergen en el texto; por ejemplo, se verá que la referencia traza hilos de continuidad a lo largo de los mundos propuestos; la estructura temática establece lindes entre párrafos y las estructuras paralelas y las repeticiones se manifiestan al interior de los párrafos.

\subsection{Estrategias de cohesión en Mì̀ ã Sibò tskìñ}

\subsubsection{Referencia}

La referencia es el mecanismo básico para hacer que el texto se mantenga cohesivamente unido. Puede verse que la referencia opera a través del texto rebasando las unidades que he llamado escenas. Por ejemplo, Sibö, el participante más tópico del Mundo de Sibö, se introduce y caracteriza en el párrafo 1 de la Escena 1 y a partir de entonces Sibörara vez es mencionado por su nombre: de sus 60 menciones en este mundo discursivo, solamente 9 se codifican por medio de nombre propio, mientras que las demás se codifican por medio de pronombre o anáfora cero. Incluso su primera mención en la Escena 2, es pronominal:

$$
\begin{array}{ll}
\text { Ie' talànẽ } & \text { dé. } \\
\text { 3S crecer.PE } & \text { llegar.PER } \\
\text { 'Él creció'. } &
\end{array}
$$


Sin embargo, en los párrafos donde los participantes más tópicos de la escena en su conjunto, Siböy Sòrbulu, no constituyen tópicos, tienden a ser mencionados por su nombre, como muestra el párrafo 13 (líneas 106-110), en donde el tópico es bikili':

(7a) Bikili’ ẽ̀ö shirìrìrì...

zorro bajar.IM IDEOF

El zorro bajó: shiririri...

(7b) Bikili’ rö tsö,

zorro COP cantor

El zorro era el cantor,

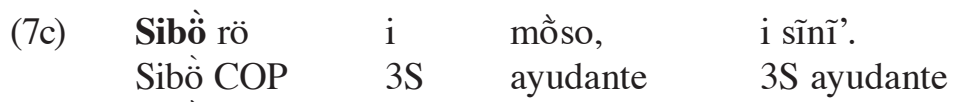

Sibö era su ayudante, su asistente.

(7d) Ie' kulùùù kulùùù kulùùù.

3S IDEOF IDEOF IDEOF

Él (tocaba el tambor).

(7e) Sòrbulu kè̀ ếnã $\mathrm{i}$ ờnẽ.

Sòrbulu NEG EXP $3 \mathrm{~S}$ caer.PE

Los Sòrbulu no entendían.

El recurso de la referencia manifiesta cadenas de identidad a lo largo del texto y estas cadenas son el elemento básico por medio del cual podemos reconocer la diferencia entre los dos mundos propuestos arriba. En el texto que nos ocupa, las cadenas de identidad en el mundo de Sibö se construyen mediante las referencias a Sibö y a Sòrbulu. En otros textos de la tradición oral bribri, la cadena de identidad que corresponde a Sòrbulu está representada por otros enemigos de Sibö. Estos participantes, antagónicos a Sibö, son caracterizados como malvados y en general son llamados diablos.

En el mundo de los cantores, las cadenas de identidad se construyen por referencia a los cantores y a los bribris, como puede verse en el siguiente ejemplo de la Escena 4: La ceremonia de sulàme $\tilde{e}^{3}$ (párrafo 22, líneas 160-176):

(8a) Wì̀ kếkëpa $\quad$ s ulà mẽ.

DEM mayor.PL 1P mano poner.IM

Ahí el mayor nos (enseñaba) a poner la mano.

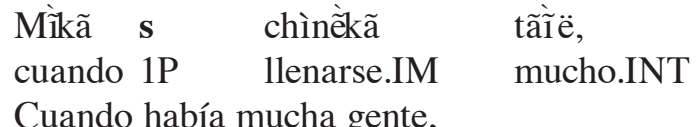

(8c) $\mathbf{0} \mathbf{s}$ ulà mẽ̀ke wö́chika

0 1P mano poner.IM solamente

solamente nos ponía la mano, 
(8d) e'se tãìë, $\mathbf{0}$ s ulà mềke wöchika è̀;

COMP muchoINT $01 \mathrm{P}$ mano poner.IM solamente nada-más cuando está muy lleno, solo enseña la parte de poner mano;

(8e) $\quad 0$ siáköl tèke,

0 instrumento tocar.IM

toca el "siáköl"4,

(8f) 0 mè̀ke

èköl ã

èköl ã

èköl ã

0 dar.IM

uno DAT

uno DAT

uno DAT

se lo da a uno, al otro, al otro,

(8g) e'

DEM COP todos

esto es, a todos,

(8h) e' rö se' wöchika.

DEM COP 1P solamente

esto es, solo a la gente (a los aprendices).

(8i) Ie' kula' ulàte,

3S asiento dar.IM

Reparte asientos,

(8j) ie' kapò bua' e' mèsẽ,

3S hamaca buena DEM poner.IM

una buena hamaca, pone eso.

(8k) E' rö tsö́kol dàtsĩ,

DEM COP cantor llegar.IM

Ahora llega el cantor,

(81) i' rö $\quad$ i sĩnĩ' dàtsĩ,

DEM COP 3S ayudante llegar.IM

llega su ayudante,

(8m) i'ẽ rö sĩn'

èköl dàtsĩ,

aquí COP ayudante uno llegar.IM

aquí llega otro ayudante,

(8n) e’tã kékëpa i che:

PROG mayor.PL $3 \mathrm{~S}$ decir.IM

entonces el mayor dice:

ööö alà érchatã ebé

ööö alà bösöla ëbë 
göö alà baëbề kaëbē alà

iwèka mĩãlë abulé, akềkèala

aalëë këkèala iãã...

$\begin{array}{llllllll}\text { (8o) } & \text { Tã } & \text { é } & \text { kếkëpa } & \text { tố } & \text { wõ̀ppèke, } & \text { i wákpa } & \text { ñì̀ kéë. } \\ & \text { PROG } & \text { aquí } & \text { mayor.PL } & \text { maraca } & \text { mover.IM } & \text { 3S mismo.PL } & \text { igual }\end{array}$

Entonces aquí el mayor mueve la maraca, los otros igual.

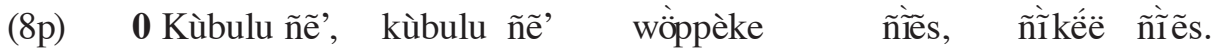

0 yesca DEM yesca DEM mover.IM también igual también

La yesca, la yesca también la mueve, (ellos) igual.

(8q) E' rö tsớkölpa tsồ.

DEM COP cantor.PL canto

Esto es canto de los cantores.

\subsubsection{Sustitución y elipsis}

Recordemos que de acuerdo con Hasan, la sustitución y la elipsis son recursos que típicamente codifican relaciones cohesivas del tipo coclasificacional. Una serie de eventos relacionados con la ceremonia pueden verse como cohesión coclasificacional. Así, en las líneas (8e-p), se introducen los siguientes eventos relacionados: tocar el siáköl, pasarlo a los aprendices, asignar asientos, colgar la hamaca, juntarse el cantor con sus ayudantes, hacer el canto ritual, tocar la maraca, remover la yesca.

El mecanismo de sustitución puede verse más específicamente en las líneas (8o-p): el cantor toca la maraca, los aprendices hacen lo mismo; mueve la yesca, los otros también. En bribri, este tipo de sustitución se codifica mediante la palabra ñì kéē 'la misma cosa'.

La elipsis puede ilustrarse con el siguiente ejemplo del párrafo 10 (líneas 81-86):

(9a) Ĩñ̃ i dáde,

TPO $3 \mathrm{~S}$ venir.PER

Hoy él vino,

$\begin{array}{ll}\text { /ulànũk } & \text { ètökicha. } \\ \text { tocar.INF } & \text { una-vez } \\ \text { y tocó una vez. } & \end{array}$

(9c) Sòrbulu kề ếnã i ồnẽ.

Sòrbulu NEG EXP $3 \mathrm{~S}$ caer.PE

Los Sòrbulu no entendían.

(9d) Bö̀tökicha,

dos-veces

Segunda vez, 
(9e) kè̀ ếnã i ờnẽ.

NEG EXP 3 caer.PE

no entendían.

(9f) Mãnãutökicha.

tres-veces

Tercera vez.

(9b), (9d) y (9f) se refieren a tres eventos diferentes, pero la acción se hace explícita solo en la primera; en las dos siguientes, la elipsis ha sido aplicada como estrategia cohesiva. En este mismo pasaje, también la repetición opera como estrategia cohesiva en (9c) y (9e) proporcionando continuidad al evento principal del párrafo.

\subsubsection{Recursos orgánicos}

La partícula cha icha, como ya se señaló, tiene la función específica de marcar la progresión (PROG) del discurso. Aunque se utiliza en los dos mundos discursivos, es mucho más frecuente en el mundo de Sibö, por ser narrativo, que en el mundo descriptivo de los cantores (19 apariciones en el mundo de Sibö y 5 en el mundo de los cantores).

Otras partículas continuativas, como e’tã, tã en las líneas (8n-o) arriba, sirven para conectar las oraciones dentro de los párrafos y también como marcadores de linde entre párrafos, como puede verse entre los párrafos 2 y 3 (línea 13: e’ shãtã), 5 y 6 (línea 47: e’tã), en el mundo de Sibö, y entre los párrafos 23 y 24 (línea 181: e’tã) en el mundo de los cantores. Algunas expresiones mayores que las partículas pueden funcionar como recursos cohesivos orgánicos; por ejemplo, en las líneass $(8 \mathrm{k}, 1, \mathrm{~m})$, las expresiones e' rö, i’ rö e i’ẽ rö, compuestas de demostrativo y cópula, funciona como indicador de progresión de las acciones involucradas, las cuales a su vez se codifican en una estructura paralela.

Los pares adyacentes tales como pregunta-respuesta son un recurso típicamente utilizado en el discurso citado, cuando el narrador inserta en su propio discurso diálogos enteros entre participantes. En el texto que se analiza aquí, se presentan casos en los que el hablante mismo atribuye una tesis a sus oyentes y luego la refuta, como puede observarse en el siguiente fragmento del párrafo 25 (líneas 187-191):

(10a) Sa' iã tã, a' talàwẽ pë' tö

1PE DAT PROG 2 P criar.IM gente ERG

Entonces para nosotros, ustedes que son criados por la gente (blanca),

(10b) e' tö i che:

DEM ERG $3 \mathrm{~S}$ decir.IM

dicen:

(10c) "Se' wíköla mìke rö si yế kố ska."

1P espíritu.DIM ir.IM DIR 1P padre lugar LOC

"Nuestro espíritu va al lugar de nuestro padre." 
$\begin{array}{lllllll}\text { (10d) } & \text { Aù, } & \text { se' } & \text { mẽ̀nẽat } & \text { sula'ö } & \text { istëu } & \text { e'̃̃ } \\ & \text { NEG } & 1 P & \text { dejar.PE } & \text { artesano } & \text { RIM } & \text { ahí }\end{array}$

No, a nosotros nos dejaron (en el lugar del) artesano

(10e) sula'deula mẽ̀at.

artesano.DIM quedarse.IM

el artesano se queda.

La conjunción es un recurso poco utilizado en el texto analizado; el elemento más importante de este tipo es la conjunción consecutiva e'kũékĩ $\sim$ e'kũée, una frase posposicional compuesta por el demostrativo $e$ ' 'aquello' y la posposición kũếkĩ $\sim k \tilde{u} \tilde{e} k$ 'por'. Se codifica con ella un predicado retórico cuya primera cláusula es la causa del estado o evento codificado en la siguiente, o dicho de otro modo, la cláusula iniciada con este elemento codifica la consecuencia del evento anterior, como se ve en el siguiente ejemplo (líneas 5 y 6):

11a) Sòrbulu e' kè̀ kĩ Sibö kiànẽ,

Sòrbulu DEM NEG EXP Sibö querer.PE

Los Sòrbulu no querían a Sibö,

11b) e'kũếkĩ ie' bák sĩốrë.

CCNS 3S EST.PE triste.INT

por eso él estaba muy triste.

En muchos casos este elemento conjuntivo señala la relación entre un párrafo y otro, y en términos generales marca también la relación de causa-efecto entre el mundo de Sibö̀ y el mundo de los cantores (es decir, de los bribris) (líneas 148-151):

12a) I mĩ̀chake kölö̀ếwã,

3S madre agarrar.PER

Agarraron a la madre,

12b) mũã́wã,

amarrar.VOL

decidieron amarrarla,

12c) i làla ttéwã.

3S hijo.DIM matar.PER

y mataron a sus polluelos.

Párrafo 19

13) $\quad$ ' ' kũếk tsãnề bèriebulu e' kî́kã $\mathrm{i}$ tò ar surùrù.

CCNS carpintero grande.PL DEM sobre $3 \mathrm{~S}$ huella AP blanca

Por eso es que los carpinteros grandes tienen una franja blanca (en el pecho). 


\subsubsection{Recursos estructurales}

Pueden reconocerse varios recursos estructurales de cohesión en el pasaje citado, particularmente repetición y paralelismo. Nótese que en las líneas (8a-d) arriba, la descripción se centra en un solo evento, inserto en una circunstancia particular: cuando hay mucha gente, el cantor solamente enseña la parte de "poner la mano" de la ceremonia. El evento se introduce en la línea (8a): los mayores enseñan la ceremonia; la circunstancia se establece en la línea (8b): cuando hay mucha gente; luego el evento se repite en (8c): ellos enseñan solo la parte de "poner la mano"; en (8d) la circunstancia se repite: cuando está muy lleno; y de nuevo se repite el evento: ellos enseñan solo la parte de "poner la mano". Esta repetición de la información propia de un fragmento del texto es típica del discurso oral descriptivo. El hablante intenta dejar muy clara ante el oyente cierta información que considera relevante y esta es la función de las repeticiones.

Las estructuras paralelas son típicas del discurso del sũwõ': las líneas (8k-m) muestran este tipo de recurso cohesivo en el cual la misma acción es realizada por diferentes agentes, que representan el elemento cambiante en la estructura paralela: el cantor viene, su ayudante viene, otro ayudante viene, y la secuencia termina con la introducción de una nueva acción: ahora el cantor canta. Otros ejemplos de paralelismos en este texto se aprecian en los párrafos 26 (líneas 195-200 y 201-203), 28 (líneas 218-220 y 222-225) y 29 (líneas 253-255) (ver anexo).

\section{Conclusión}

La cohesión textual se construye así en el discurso por medio de una serie de recursos cohesivos que trabajan en diferentes niveles de la organización textual. La referencia permite trazar cadenas de continuidad a lo largo de los mundos propuestos. Las continuidades de tópico, tiempo y escenario y la estructura temática permiten establecer lindes entre párrafos, mientras que las estructuras paralelas y las repeticiones se despliegan a través de secuencias de cláusulas que componen párrafos. Hemos visto así cómo la función textual del lenguaje aparece reflejada tanto en la estructura del texto como en los recursos lingüísticos que permiten interpretarlo como un todo coherente y cohesivo.

\section{Notas}

1. La traducción de las citas es mía.

2. Las ligas coextensivas se dan cuando dos elementos léxicos se encuentran en relación de sentido. Básicamente, las relaciones de sentido que pueden darse entre dos elementos léxicos en relación coextensiva son: 1) Sinonimia: el significado experiencial de ambos elementos es idéntico. 2) Antonimia: el significado experiencial de ambos elementos es opuesto. 3) Hiponimia: la relación entre ambos elementos es de "clase inclusiva" (o supraordinado) y "miembro incluido" (o hipónimo). Los varios miembros de una misma clase se encuentran en relación de cohiponimia. 4) Metonimia: la relación entre los dos elementos es de una parte con el todo. Las varias partes de un todo se encuentran en relación de cometonimia. 5) Repetición de elementos léxicos: se establece una relación semántica entre elementos léxicos repetidos, los cuales pueden ser idénticos o estar codificados en formas morfológicamente diferentes (como comprar/compró). En este trabajo no se analizan las relaciones de sentido. 
3. La ceremonia de sulàmẽ, literalmente 'poner nuestra mano' se refiere específicamente a la enseñanza de tocar los objetos ritualmente y era parte de la iniciación a ciertos cargos como los de awá 'médico', óköm 'enterrador', sĩõ'tãmĩ 'encargada de las piedras curativas', etc.

4. Siáköl: instrumento musical de percusión que se utilizaba en la ceremonia fúnebre.

5. Sula', el artesano, y no Sibö, es quien crea a los seres humanos; cada ser humano tiene su propio Sula', su creador, que permanece haciendo a la persona a lo largo de su vida.

\section{Bibliografía}

Borge, Carlos, et al. 1994. La Educación en el territorio indígena Bribri-Cabécar de Talamanca. San José: UNICEF-Ministerio de Educación Pública.

Brody, Jill. 1986. "Repetition as a rhetorical and conversational device in Tojolabal (Mayan)". International Journal of American Linguistics. 52 (3): 255-74.

Brown, Gillian \& George Yule. 1993. Análisis del discurso. Madrid: Visor Libros.

Clark, Herbert H. 1977. “Bridging”. En P.N. Johnson-Laird and P.C. Wason (eds.). Thinking: Readings in cognitive science, 411-20. Cambridge: Cambridge University Press.

Firth, J.R. 1935. "The technique of semantics". Transactions of the Philological Society, reprint 1959. Papers in linguistics 1934-1951. London: Oxford University Press.

Givón, Talmy. 1984. Syntax: A functional-typological introduction. Vol. 1. Amsterdam: John Benjamins.

1990. Syntax: A functional-typological introduction. Vol 2. Amsterdam: John Benjamins.

Gleason, H.A. Jr. 1968. Contrastive analysis in discourse structure. Georgetown University Monograph series on Languages and Linguistics. 21: 39-64.

Grimes, Joseph. 1975. The thread of discourse. The Hague: Mouton.

Halliday, M.A.K. 1967. "Notes on transitivity and theme in English, Parts 1 and 2". Journal of Linguistics. 3: 37-81, 199-244.

1968. "Notes on transitivity and theme in English, Part 3". Journal of Linguistics. 4: $179-215$. 
1970. “Language structure and language function”. En: Lyons, John (ed.). New horizons in linguistics, 140- 65. Middlesex: Penguin Books.

Halliday M.A.K. y Ruqaiya Hasan. 1989. Language, context and text: Aspects of language in a social-semiotic perspective. Oxford: Oxford University Press.

Jakobson, Roman. 1968. "Poetry of grammar and grammar of poetry”. Lingua. 21: 597- 609.

Jara Murillo, Carla Victoria. 1995a. Text and Context of the Sũwõ': Bribri Oral Tradition. Tesis doctoral inédita. Louisiana State University.

1995b. "Transitividad en el discurso bribri”. Revista de Filología y Lingüística de la Universidad de Costa Rica. 21 (2): 92- 105.

2003. “Codificación de participantes en una narración bribri”. Estudios de Lingüística Chibcha. 22: 33- 60.

2004. "Observaciones para el estudio dialectológico de la lengua bribri”. Estudios de Lingüística Chibcha. 23: 89- 120.

Longacre, R.E. 1976. An anatomy of speech notions. Lisse: Peter de Ridder.

Malinowski, B. 1923. "The problem of meaning in primitive languages. Supplement 1". En Odgen, C.K. \& I.A. Richards (eds.). The meaning of meaning. London: Kegan Paul.

1935. Coral gardens and their magic. Vol. 2. London: Allen \& Unwin.

\section{Anexo}

\section{Mì̀ã Sibồ tskìnẽ Cuando Sibò nació}

\section{El Mundo de Sibö}

\section{Escena 1: El nacimiento de Sibò}

Párrafo 1

1) Mì̀ã icha $s$ bulu $e^{\prime}$ tsikìnẽ

TPO PROG 1P jefe DEM nacer.PE

Cuando nuestro jefe nació 


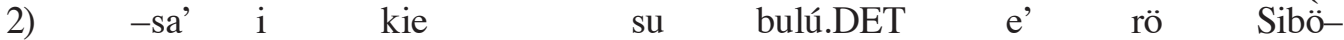 $1 \mathrm{P} \quad 3 \mathrm{~S}$ llamar.IM $1 \mathrm{P}$ jefe DEM COP Sibö -nosotros lo llamamos nuestro jefe, ese es Sibö-

3) e' tsikìnẽ,

DEM nacer.PE

él nació

4) e'tã icha Sòrbulukẽ̀ kĩ cha ie' kiànẽ.

PROG PROG Sòrbulu NEG EXP PROG $3 \mathrm{~S}$ querer.PE

entonces los Sòrbulu no lo querían.

5) Sòrbulu e' kề kĩ Sibồ kiànẽ,

Sòrbulu DEM NEG EXP Sibö querer.PE

Los Sòrbulu no querían a Sibö,

6) e'kũếkĩ ie' bák siồrë.

CCNS 3S EST.PE triste.INT

por eso él estaba muy triste.

7) I mî̀ wã ie' mî̀nềtsẽ kố aiẽ, 3S madre AG $3 \mathrm{~S}$ ir.PE.DIR lugar allá- arriba

Su madre lo llevó a un lugar allá arriba

8) e'ẽ ie' talànẽ.

ahí 3S crecer.PE

ahí él creció.

Párrafo 2

9) Mĩ̀kã ie' kũ̀nẽ,

TPO $3 \mathrm{~S}$ nacer.PE

él nació,

10) iètã Sibồ tsikìnẽ kố diàe,

PROG Sibồ nacer.PE lugar allá- abajo

entonces Sibö nació en un lugar allá abajo,

11) - - ñẽ' $^{\prime}$ ye' $\quad$ kố $\quad$ ốrtsèke $\quad$ e'ẽ.

DEM 1S lugar contar.IM ahí

-en ese lugar que estoy contando.

12) E'tã krò tchërkĩ cha ờr: kòtereööö.

PROG gallo AP PROG gritar.IM IDEOF

Entonces un gallo que estaba ahí gritó: cotereuuu. 
Párrafo 3

13)

$\begin{array}{llllllll}\text { E' shãtã } & \text { pë’ } & \text { durkĩ } & \text { èköl } & \text { e' } & \text { r } & \text { i } & \text { yé; } \\ \text { PROG } & \text { persona } & \text { AP } & \text { una } & \text { DEM } & \text { COP } & 3 S & \text { padre }\end{array}$

Entonces un ser que estaba ahí era su padre;

14) e' rö Sibökõmõ.

DEM COP Sibökõmõ

ese era Sibökõmõ.

15) E' õ̀mĩk Sòrbulu këkëla durkĩ,

DEM LOC Sòrbulu señor.DIM AP

A su lado estaba un señor Sòrbulu

16) e’tã bök ie’pa dé.

PROG dos 3P llegar.PER

entonces eran dos.

17) $\mathrm{E}^{\prime}$ kebèrke $\mathrm{e}^{\prime}$ icha

DEM quejarse.IM DEM PROG

Ellos se estaban quejando

18) kố i’ kồs $\quad \mathrm{e}^{\prime} \quad \mathrm{r} \quad$ ie'pa kố

lugar DEM todo DEM COP 3P lugar

que todo ese lugar era de ellos,

19) e'kũếkĩ yí kề kiàrtã ie'pa kĩ.

CCNS quién NEG querer.IM 3P EXP por eso ellos no querían a nadie (por ahí).

Párrafo 4

20) Mì̀ ã ie'pa kukuồ ã krò ồr: kòtereööö, TPO 3P oído EXP gallo gritar.IM IDEOF

Cuando oyeron al gallo gritar: kotereuuu,

21) ก̃ẽ ẽ e' rö i chè:

PROG DEM ERG 3S decir.IM

entonces dijeron:

22) "I tsikìnẽ je'?"

3S nacer.PE AFIR

“De veras nació?" 
23) Èköl pë’ durkĩ e' $r$ i chè: una persona AP DEM ERG $3 S$ decir.IM Una persona que estaba ahí dijo:

24) "Tö, Sibö tsikìnẽ".

AFIR Sibò nacer.PE

"Sí, Sibö nació."

25) E' kũếk Sòrbulu mồso yulè tã̃ DEM por Sòrbulu ayudante buscar.IM muchos Por eso los Sòrbulu buscaron muchos ayudantes

26) /se' ttókulur, $1 \mathrm{P}$ matar.FIN.PL

/para matar a la gente,

27) /se' ttókulur alàr alar kốs alákölpa. 1P matar.FIN.PL niño.PL todo mujer.PL /para matar a todos los niños y las mujeres.

Párrafo 5

28) I mî̀wöla tö i chè: 3S madre.DIM ERG 3S decir.IM

Su madre dijo:

29) "Ye' alàla duwöràwã; IS hijo.DIM morir.F/P

"Mi hijo morirá,

30) yì e' mẽ' mì̃ã quién DEM ojalá ir.IM ¿quién fuera

31) /i balö̀ $\quad$ yu wếtsë à 3S esconder.INF 1S COM allá-arriba /a esconderlo conmigo allá arriba,

32) /wẽ kékëpa Sibö̀õmõ tã sa' dếdëkã?" donde señor Sibökõmõ $\mathrm{COM}$ 1PE llegar.PE /adonde fuimos con el señor Sibökõmõ?" 
33) E' rö pë' kie cha Áksula

DEM COP persona llamarse.IM PROG Áksula Había un ser llamado Áksula,

34) e' tö i chè icha:

DEM ERG $3 \mathrm{~S}$ decir.IMPROG

que dijo:

35) 'Ye' wã i tchốkãmĩ

1S AG $3 \mathrm{~S} \quad$ ir.F/P

"Yo lo llevaré

36) e' kề sũwềppa yì wã."

DEM NEG ver.F/P quién AG

adonde no sea visto por nadie."

37) "Ẽmã mî́shkã."

AFIR ir.HORT

"Bien, vamos."

38) Áksula ẽ tchéwã

Áksula REF comenzar.PER

Áksula se puso

39) /ñõol̃ yawè icha e' dikî̀ ã.

camino hacer.IM PROG DEM abajo LOC

/a cavar un camino subterráneo.

40) Këkëpa dàã,

señora llegar.IM

La señora venía,

41) dékã jaiẽ.

llegar-hasta.PER allá-arriba

llegó allá arriba.

42) Mî̀kã ie' dékã kố aiẽ, TPO 3S llegar-hasta.PER lugar allá-arriba

Cuando ella llegó allá arriba,

43) kố $\quad$ aĩ̃ $\quad$ e'ẽ $\quad$ kố $\quad$ kie

lugar allá-arriba ahí lugar llamarse.IM

ese lugar allá arriba se llama 
44) -aĩẽ ie' sẽ̀nẽ-

allá-arriba $3 \mathrm{~S} \quad$ vivir.PE

-allá arriba él vivió-

45) e’ẽ kố kie:

ahí lugar llamarse.IM

ese lugar se llama:

dììratuã, lòòòratuã

dìraià, lòraià

46) e'ẽ ie' dékã.

ahí 3S llegar-hasta.PER

ahí llegó ella.

Párrafo 6

47) E’tã tsáwak ù mẽrkã tãĩ ë.

PROG hormigas casa AP grande.INT

Entonces ahí estaba la gran casa de las hormigas.

48) Ñẽ'ẽ kë’këla Áksula tö i ché:

PROG señor Áksula ERG 3S decir.IM

Entonces el señor Áksula dijo:

49) 'Yì e' ye' kî̀mẽ̀mĩ cha?

quién DEM $1 \mathrm{~S}$ ayudar.F/P PROG

“Quién me ayudará?

50) Këkë Sibölala ttèkèwã cha ie'pa tö.

señor Sibö.DIM matar.IM PROG 3P ERG

Ellos matarán al señor Sibö .

51) Sòrbulu tö cha ie' yulè ar."

Sòrbulu ERG PROG 3S buscar.IM AP

Los Sòrbulu lo están buscando.”

52) Tsáwak tö i che:

hormigas ERG 3S decir.IM

Las hormigas dijeron:

53) “Ye', ye', ye'..."

1S 1S 1S

"Yo, yo, уо..." 
54) Ù shũ̀ ikalè tã̃ì, casa dentro limpiar.IM grande Abrieron (un espacio) grande en la casa,

55) e'ẽ i pàtchồwã, ahí 3S poner.IM ahí lo pusieron,

56) e'ẽ Sibö̀ talànẽ.

ahí Sibö crecer.PE

ahí Sibö creció.

Escena 2: El mal agüero de bikili' 'el zorro'

Párrafo 7

57) Ie' talànẽ dé.

3S crecer.PE llegar.PER

Él creció.

58) mî̀k ie' dé wếm èkkë,

TPO 3S llegar.PER hombre COMP

Cuando llegó a hombre,

59) ie' i yế ã i che:

$3 S$ POS padre DAT $3 S$ decir.IM

le dijo a su padre:

60) “A, yếwöla, ye' mî̀ãnẽ dià̃.

VOC padre.DIM 1S ir.IM allá-abajo

"Oh, padrecito, yo voy a ir allá abajo.

61) İs icha Sòrbulu $\mathrm{e}^{\prime}$ kề kĩ ye' kiànẽ? cómo PROG Sòrbulu DEM NEG EXP 1S querer.PE ¿Cómo es (eso de) que los Sòrbulu no me quieren?

62) E’kũếkĩ ye' mìãnẽ

CCNS 1S ir.IM

Por eso yo voy a ir

63) / / sẫũk."

3S ver.INF

a verlos." 
64) I yé $\quad$ i iũ̀te:

$2 \mathrm{~S}$ padre $3 \mathrm{~S}$ responder.IM

Su padre le responde:

65) "Ba yúshka

2S ir.HORT

"Vaya,

66) erë be mĩã wồbala wa.

pero $2 S$ ir.IM ojo INST

pero vaya con cuidado.

67)
Pë'e' be'
ttèwã."
gente DEM2S
matar.IM
Esa gente te va a matar."

Párrafo 8

68) I bitẽ̃ã;

3S venir.PER

Él se vino;

69) ì daché tã̃ bitế ie' wã, algo hueso grande venir.PER $3 \mathrm{~S} \quad \mathrm{AG}$ trajo un hueso grande de algo,

70) kî́kã $\quad \mathrm{i} \quad$ tso $\quad$ tchabềköl $\quad$ sũ̀, $\quad$ pũ̀ $\quad$ sũ̀, $\quad$ ì $\quad$ sũ̃ encima 3S EST serpiente parecido águila parecido algo parecido sobre el cual había imágenes como de serpientes, águilas y alguna otra cosa.

Párrafo 9

71) Sòrbulu kố ska Sòrbulu mî́yal dià

Sòrbulu lugar LOC Sòrbulu ir.PER.PL allá-abajo

En el lugar de los Sòrbulu, estos se encontraban allá abajo

72) /kãnềbalök:

trabajar.INF

/trabajando

73) 'Be' i tsè

2S 3S escuchar.IM

"Escuchas 
74) /ì ulàrke: wềk, wềk, wềk?"

algo sonar.IM IDEOF

algo que suena: wek, wek, wek?

75) Ie'pa dé

3P llegar.PER

Ellos fueron

76) /i wébalök.

3S examinar.INF

a examinar.

77) Kề yì kũ.

NEG quien EST.NEG

No había nadie.

78) Bikili' sí arkĩ,

zorro seco AP

El zorro seco estaba colgado,

79) e' ar,

DEM AP

estaba colgado,

80) bikili’ Sòrbulu chaké arkĩ.

zorro Sòrbulu comida.DET AP

el zorro, que es la comida de Sòrbulu, estaba colgado.

Párrafo 10

81) Ĩ̃̃̃ i dáde

TPO 3S venir.PER

Hoy él vino

82) /ulànũk ètökicha.

tocar.INF una-vez

y tocó una vez.

83) Sòrbulu kề ếnã i õ̀nẽ.

Sòrbulu NEG EXP $3 S \quad$ caer.PE

Los Sòrbulu no entendían. 
84) Bötökicha, dos-veces

Segunda vez,

85) kè̀ ếnã i önẽ.

NEG EXP 3S caer.PE no entendían.

86) Mãnãätökicha.

tres-veces

Tercera vez.

87) E’tã i wák tö bikéitse:

PROG 3S mismo ERG pensar.IM

Entonces él pensó para sus adentros:

88) 'Sòrbulu e' mẽ' ye' bikéitse,

Sòrbulu DEM ojalá $1 \mathrm{~S}$ pensar.IM

"Espero que Sòrbulu piense en mí así:

89) “Ñ̃'se alè rö Siböla sulàre

DEM.COMP talvez COP Sibö.DIM RIM

"Eso que suena talvez es Sibö

90) /tso' wõ̀yök balök".

EST mal-agüero hacer.INF

haciéndonos mal agüero".

91) “Icha se' è̀rdàwã,

PROG 1P desaparecer.F/P

"Vamos a desaparecer

92) e'se wếrtsök i tso'.

DEM.COMP mal-agüero $3 \mathrm{~S}$ EST

esto es como mal agüero

93) Sṹ,

ver.IMP

Vea

94) se' ã̃̃̀̀bölö́wã $\quad$ i $\quad$ yök!"

$1 \mathrm{P}$ escondernos.IMP $3 \mathrm{~S}$ ante

¡escondámonos de él! 
95) Ie'pa ãñìibule dur,

3P esconderse.IM AP

Estaban escondidos,

96) böka bërë.

dos quieto

los dos quietos.

Párrafo 11

97) I dátske cha;

3S llegar-directo.PER PROG

Él llegó directo,

98) bikili' arkĩ cha,

zorro AP PROG

el zorro estaba colgado,

99) e' pë' chaké ar;

DEM gente comida.DET AP

la comida de esa gente estaba colgando;

100) e' wö̀ike cha: fffu, fffu...

DEM soplar.IM PROG IDEOF

él lo sopló: fffu, fffu...

Párrafo 12

101) Sa' wö̀mè̀kètsãtche

1PE estar-designado.IM.ING

Nosotros ya estábamos designados

102) /ãñ்̃ ttökwã tếruwak tã

REC matar.INF téribes COM

para matarnos con los téribes,

103) e'kũếkĩ chè i dör icha:

CCNS decir.IM 3S ERG PROG

por eso él dijo:

baa tĩõmî́nkũã, yaa tĩõmî́nkũã

baa kulùmî́nkũã, yaa kulùmî́nkũã

baa chirimînkũã, yaa chirimînkũã 


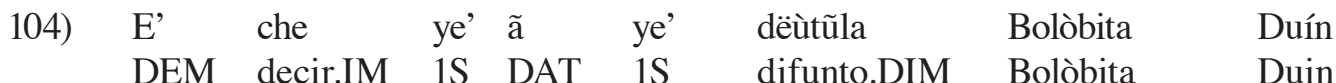
Esto me dijo mi difunto Duín, de Bolòbita,

105)

$\begin{array}{llll}\text { tö } & \text { nẽ'es } & \text { i } & \text { che. } \\ \text { que } & \text { DEM.COMP } & 3 S & \text { decir.IM } \\ \text { que así lo dijo. } & & \end{array}$

Párrafo 13

106) Bikili’ ề ö shirìrìrì...

zorro bajar.IM IDEOF

El zorro bajó: shiririri...

107) Bikili' rö tsö , zorro COP cantor

El zorro era el cantor,

108) Sibö̀ rö i mõ̀so, $\mathrm{i}$ iñ̃ .

Sibö COP 3S ayudante $3 \mathrm{~S}$ ayudante

Sibö era su ayudante, su asistente.

109) Ie' kulùùù, kulùùù, kulùùù .

3S IDEOF IDEOF IDEOF

Él (tocaba el tambor).

110) Sòrbulu kề énã i ờnẽ.

Sòrbulu NEG EXP $3 \mathrm{~S}$ caer.PE

Los Sòrbulu no entendían.

Párrafo 14

111) E'se rö iõiờtã,

COMP COP antes

Esto era antes,

112) sa' iã i mẽ̀at,

1PE DAT 3S dejar.IM

(cuando) nos dejaron estas cosas,

$\begin{array}{lllll}\text { 113) iõiồtã } & \text { sa } & \text { sulàrke } & \text { 1̃ã, } \\ & \text { TPO } & 1 P & \text { hacer-funeral.IM } & \text { todavía }\end{array}$

antes cuando todavía hacíamos las ceremonias fúnebres, 
114) sa belório tchöù̀ ẽ $\quad$ ĩã,

1P velorio celebrar.IM todavía

cuando todavía celebrábamos los velorios,

115) e’tã su duwö̀ã

tsìralala,

PROG 1P morir.IM pequeño.DIM

entonces, cuando alguien moría pequeño,

116) e'tã i ulàwẽ̀kẽ;

PROG 3S hacer-funeral.IM

entonces se le hacía la ceremonia fúnebre;

117) e’tã kêkëpa tö i chè:

PROG mayor.PL ERG 3S decir.IM

entonces los mayores decían:

aa rtsölala, rtsö kuë i tèè,

kërè ë, kërè ë, ööö...

àà bimãlè rtsö kuë i àà,

kërè ë, kërè ë, ööö...

Párrafo 15

118) Bikili’ tsö ke,

zorro cantar.IM

El zorro cantaba,

119) e’tã Sibồ cha rö ñẽ tté wöñã̃rke

PROG Sibö PROG ERG DEM palabra.DET cortar.IM entonces Sibö cortaba la palabra de aquel,

120) tã ie' sh-sh-sh-sh.

PROG 3S IDEOF

tocando la maraca.

Párrafo 16

121) Ñ̃ẽ Sòrbulu ẽ' balé tulur

PROG Sòrbulu REF esconder.PER AP

Entonces los Sòrbulu, que estaban escondidos,

122) /e' tö i che:

DEM ERG 3S decir.IM

dijeron: 
123) "Ì rö, kírö?"

qué COP RIM

"Qué es eso?"

124) Sòrbulu $\mathrm{r} \quad \mathrm{i}$ tché lanzawa: ffft.

Sòrbulu ERG 3S punzar.PERlanzaINST IDEOF

Los Sòrbulu lo punzaron con una lanza: ffft...

125) I burkã àt,

3S AP por-el-aire

pero él voló por los aires,

126) tcháshkal!

escapar.PE

¡se escapó!

127) Wế i dawö !

dónde 3S morir.IM

¡Qué se iba a morir!

Párrafo 17

128) Ie’pa tso' ñì̀ppök Sibö tã,

3P EST pelear.INF Sibö COM

Ellos estaban peleando con Sibö,

129) dalèwa aì bikili'sí démĩ ar bö tsốkã.

mientras allá-arriba zorro seco llegar.PER.RE AP fuego encima

mientras tanto, el zorro volvió a colgarse encima del fuego.

130) Sòrbulu lùnẽ̀kã:

Sòrbulu enfurecerse.PE

Los Sòrbulu se enfurecieron:

131) "I'se su wếrtse irtse;

DEM.COMP 1P hacer-mal-agüero.IM RIM

"Esto es como que nos está haciendo mal agüero;

132) su duwöràwã!"

1P morir.F/P

¡nos vamos a morir!” 
133) Bikili' kölöwếwã,

zorro agarrar.PER

Agarraron al zorro,

134) wöté: kó kó kó,

picar.PER IDEOF

lo picaron,

135) péũmĩ;

botar.PER

y lo botaron;

136) kề $\quad$ i $\quad$ wã $\quad \mathrm{i}$ tsốkönằnẽ.

NEG 3P AG 3S probar.PE

no lo probaron.

137) E'kû́ek bikili' kẽ̃ katànõk;

CCNS zorro NEG comer.FIN

Por eso es que el zorro no es para comerlo;

138) i tsốkuồpa,

3S probar.F/P

si lo hubieran probado

139) ẽmã i katànõk.

entonces 3S comer.FIN

entonces se comería.

Escena 3: El mal agüero de tsãne $\dot{\tilde{e}}^{\prime} e l$ pájaro carpintero'

Párrafo 18

140) Iskà mĩ̃̃

de-nuevo ir.IM

De nuevo fue

141) /wĩ̃ ê Sòrbulutso' tầì

allá Sòrbulu EST muchos IDEOF

allá donde había muchos Sòrbulu haciendo escándalo,

142) tsãnẽ̀ pàtchốwã pë’ sế ã. carpintero meter.PER gente poste LOC y metió un pájaro carpintero en un horcón de (esa) gente. 
143) Sórbulu kebèrke: lölölö.

Sòrbulu hacer-ruido.IM IDEOF

Los Sòrbulu hacían mucho escándalo: lololo...

144) Tsãnẽ̀ e é pökkã: tsãnẽ̀nẽ̀nẽ̀...

carpintero REF lanzar.IM IDEOF

El pájaro carpintero alzó vuelo...

145) “Ö̈öö!"

INTJ

“Ohhh!”

146) Tsãnè̀ $\quad$ ñẽ' làla tã'tche,

carpintero DEM hijo.DIM tener.ING

Aquel carpintero ya tenía polluelos,

147) détche bëriebulu.

llegar.PER.ING grande.PL

ya estaban grandecitos.

148) I mĩ̀chake kölöwếwã,

3S madre agarrar.PER

Agarraron a la madre,

149) mũấwã,

amarrar.VOL

decidieron amarrarla,

150) i làla ttéwã.

3S hijo.DIM matar.PER

y mataron a sus polluelos.

Párrafo 19

151) E' kũẽ́k tsãnẽ bëriebulu e' kî́kã i tồ ar surùrù.

CCNS carpintero grande.PL DEM sobre $3 \mathrm{~S}$ huella AP blanca Por eso es que los carpinteros grandes tienen una franja blanca (en el pecho).

152) E' rö cha,

DEM COP PROG

Esto es así, pues 
153)

$\begin{array}{llll}\text { Sòrbulu i } & \text { mõ’wã } & \text { wõ̀yök } & \text { kũếk. } \\ \text { Sòrbulu 3S } & \text { amarrar.PER } & \text { mal-agüero } & \text { por } \\ \text { los Sòrbulu lo amarraron por el } & \text { mal agüero. } & \end{array}$

Párrafo 20

154) I mũẽ̀ tchër; 3S amarrar.IM AP

La tenían amarrada;

155) bếrë ie’pa i sãwẽ̀ aì, más-tarde $3 \mathrm{P} \quad 3 \mathrm{~S} \quad$ ver.IM allá-arriba más tarde la ven allá arriba,

156) tsãnẽ̀ démĩ ar dikó kĩ. carpintero llegar.PER.DIR AP pejibaye sobre la carpintera fue a pegarse en el pejibaye.

Párrafo 21

157) E' mềat sa', tsốkölpa ã;

DEM quedar.IM 1PE cantor.PL DAT

Esto quedó para nosotros, los cantores;

$\begin{array}{lllll}\text { e'tã } & \text { i } & \text { chè } & \text { i } & \text { di: } \\ \text { PROG } & 3 S & \text { decir.IM } & \text { 3S } & \text { ERG }\end{array}$

entonces ellos decían:

ie kồksala wakabawaee

ie kõibölö wakabawaaa

bösölaikabë wakabawaee

wakabawa arbaià armawee

aekëkëawaa öiaa;

ieã kốrsala wakabawaee

ia sòrbölö wakabawaaa

bösölaikabë wakabawaee

wakabawa arbaià armawee

aekëkëawaa öaee

159) E' kề rö awá iã, sulàwõie.

DEM NEG COP médico DAT funeral.COMP Este no es para médico sino para funerales. 


\section{El Mundo de los cantores}

Escena 4: La ceremonia de sulàmẽ ('poner nuestra mano')

Párrafo 22

160) Wì̀ kékëpa $\mathrm{s}$ ulà mẽ.

DEM mayor.PL 1P mano poner.IM

Aquellos mayores nos (enseñaban) a poner la mano.

161) Mĩ̀nã $\mathrm{s}$ chìnẽ̀ kã tãĩë,

TPO 1P llenarse.IM mucho.INT

Cuando había mucha gente,

162) s ulà mề ke wö́chika,

$1 \mathrm{P}$ mano poner.IM solamente

solamente nos ponían la mano,

163) e'se tãüe, $\mathrm{s}$ ulà mề ke wóchika è.

DEM.COMP mucho.INT 1P mano poner.IM solamente nada-más cuando está así de lleno, solamente (enseña la parte de) poner la mano.

164) Siáköl tèke,

instrumento tocar.IM

Toca el instrumento,

165) mẽ̀ke èköl ã, èköl ã, èköl ã,

dar.IM uno DAT uno DAT uno DAT

se lo da a uno, al otro, al otro,

166) e' rö wĩ̀ kốs,

DEM COP todos,

esto es, a todos,

167) e' rö se' wö́chika.

DEM COP 1P solamente

esto es, solo a la gente (a los aprendices).

168) Ie' kula' ulàte,

3S asiento repartir.IM

Reparte asientos,

169) ie' kapö bua' e' mẽ̀sẽ.

3S hamaca buena DEM poner.IM

una buena hamaca, pone eso. 
170) $E^{\prime}$ rö tsökol dàtsĩ,

DEM COM cantor llegar.IM

Ahora llega el cantor,

171) i' rö $\quad$ i sĩnĩ' dàtsĩ,

DEM COP 3S ayudante llegar.IM

llega su ayudante,

172) i'ẽ rö sĩñ̃ èköl dàtsĩ,

aquí COP ayudante uno llegar.IM

aquí llega otro ayudante,

173) e’tã kékëpa i che:

PROG mayor.PL $3 \mathrm{~S}$ decir.IM

entonces el mayor dice:

ööö alà érchatã ebé

ööö alà bösöla ëbë

göö alà baëbë kaëbè alà

iwèka mĩ̃ãlë abulế, akèkèala

aalëë këkëala iãã...

174) Tã i’ẽ kékëpa tố wöppèke, i ñìkéë.

PROG aquí mayor.PL maraca mover.IM $3 \mathrm{~S}$ mismo.PL igual

Entonces, aquí el mayor mueve la maraca, los otros igual.

175) Kùbulu ñẽ', kùbulu ñẽ' wò ppèke ñĩ̃ẽs, ñìkéë ñ̀̃̃̃s.

yesca DEM yesca DEM mover.IM también igual también

La yesca, la yesca también la mueve, igual.

176) E' rö tsökölpa tsö̀.

DEM COP cantor.PL canto

Esto es canto de los cantores

177) Ye' tsö̀ uuuuuu...

1S cantar.IM INTJ

Yo canto uhh (muchísimo)

Párrafo 23

178) Íyi ulìtãnẽ tsé tã',

cosa todas canto.DET tener

Todas las cosas tiene su canto, 

179) wẽ's awápa a i è como médico.PL DAT 3S quedar.PER así así como (los que ) quedaron para los médicos,

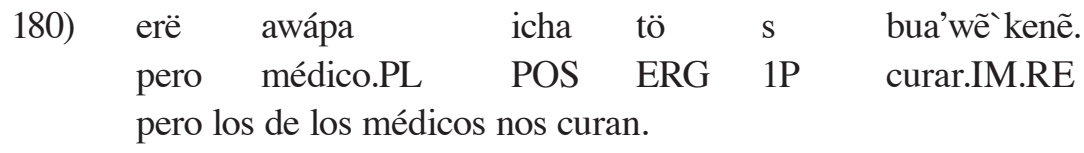

\section{Escena 5: El lugar de Sula' (el artesano)}

Párrafo 24

181) E'tã ñẽ PROG DEM COP

Entonces eso es
/se' dúwã bák
e' wíköla
$\tilde{\mathrm{a}}$
$1 \mathrm{P}$ muerto EST.PE
DEM espíritu.DIM
DAT

para el espíritu de alguien que está muerto

183) le' dióköla tulurkĩ

DEM imagen.DIM AP.PL

sus imágenes que están (por ahí)

184) /e' kĩ ñõlõ̀ ñì̃wẽ̀ketche,

DEM EXP camino iluminar.IM.ING

a ellas se les ilumina el camino

\begin{tabular}{|c|c|c|c|}
\hline 185) & $\begin{array}{l}\text { shkómĩ } \\
\text { caminar.FIN.INC }\end{array}$ & $\begin{array}{l}\text { ie, } \\
\text { como }\end{array}$ & \\
\hline & para que empiecen & & \\
\hline 186) & dö̀ñ & sulé & kố \\
\hline & ir.IM.RE & artesano.DET & lugar \\
\hline
\end{tabular}

Párrafo 25

187) Sa' iã tã, a' talàwẽ pë' tö 1PE DAT PROG 2P criar.IM gente ERG Entonces para nosotros, ustedes que son criados por la gente (blanca) 
188) e' tö i che:

DEM ERG 3S decir.IM

dicen esto:

189) “Se' wíköla mĩ̀ke rö si yé kố ska." 1P espíritu.DIM ir.IM hasta 1P padre lugar hasta "Nuestro espíritu va hasta el lugar de nuestro padre."

190) Aù, se' mẽ̀nẽat sula'ö NEG 1P dejar.PE artesano RIM ahí

No, a nosotros nos dejaron (en el lugar del) artesano,

191) sula'deula mẽ̀at, artesano.DIM quedarse.IM el artesano se queda

192) e' kũếk kékëpa tulúãt

CCNS mayor.PL ser-dejado.PE

por eso los señores (los artesanos) fueron dejados

193) /se' yuwök.

1P hacer.INF

haciéndonos.

194) E'ẽ se' yörke.

ahí 1P ser-hecho.IM

Ahí nos hacen.

Párrafo 26

195) Wákpa tso’sẽ

mismo.PL EST.PL

(De) esos (artesanos) que hay

196) /kie ] Sòrsö,

llamarse.IM Sòrsö

(unos) se llaman Sòrsö,

197) wákpa tso’

mismo.PL EST

(de) esos que hay

198) /kie Sulàtsũk,

llamarse.IM Sulàtsũk

(uno) se llama Sulàtsũk 
199) wákpa tso’sẽ

mismo.PL EST.PL

(de) esos que hay

200) /kie Sulàlaköl, Sulàböte, Téksula.

llamarse.IM Sulàlaköl Sulàböte Téksula.

(unos) se llaman Sulàlaköl, Sulàböte, Téksula.

201) E’ẽ se' yörke,

ahí 1P ser-hecho.IM

Ahí nos hacen,

202) e'ẽ se' kãnẽ̀̃

ahí 1P ser-trabajados.IM

ahí nos trabajan.

203) e’ẽ pë' tso' tãìï.

ahí gente EST mucho.INT

ahí hay mucha gente.

\section{Párrafo 27}

204) Mĩ̀ sẽ duwöráwã,

TPO 1P morir.IM

Cuando la gente muere,

205) e'tã kố i’ kĩ be' sẽ̀r

PROG lugar DEM LOC $2 \mathrm{~S}$ vivir.IM bien.INT

si en este mundo usted ha vivido bien,

206) e’tã be' wíköla ñẽ'ẽ mĩ̃ã ia:

PROG 2S espíritu.DIM ahí ir.IM

entonces su espíritu va allá:

nẽtabà nẽgolià...

207) E’tã be' mĩ̀chò è̀, PROG 2S irse.IM nada-más

Cuando usted se va definitivamente,

208) e' dàmĩkã aì shồ

DEM pasar.IM allá-arriba exactamente

pasa por allá arriba, exactamente 
209) / /

lugar llamarse.IM

por un lugar que se llama:

kuàtarà rötalaë

kuàtilië rötilië

210) Tãì̈ $\quad$ guardia tso'.

mucho.INT guardia EST

Hay muchos guardianes.

211) Be' dàmĩkã,

2S pasar.IM

Cuando usted pasa,

212) pë' s chàke:

gente 1P preguntar.IM

(esa) gente le pregunta:

213) “A, ditsö, be' dàmĩtche?"

VOC semilla $2 \mathrm{~S}$ pasar.IM.ING

"Oiga, semilla, ¿ya se va?"

214) Che:

decir.IM

(Usted) dice:

215) “Tö, ẽmã”.

AFIR AFIR

"Sí, sí."

Párrafo 28

216) E'kũếk sa' ã kốwö mếat

CCNS 1PE DAT tiempo dejar.PER

Por eso a nosotros nos dejaron (unas reglas),

217) su duwöwã,

$1 \mathrm{P}$ morir.IM

(cuando) uno muere,

218) tã ồbulu bièke,

PROG yesca escarbar.IM

entonces le escarban la yesca, 
219) istë balèke,

manojo contar.IM

le cuentan el manojo,

220) ya' tèke;

molejónpicar.IM

le pican el molejón,

221) vaca tốule su wã,

vaca comprar.ANT $1 \mathrm{P} \quad \mathrm{AG}$

si ha comprado vacas,

222) e'tã vaca tèke,

PROG vaca matar.IM

entonces matan una vaca

223) köchi tèke,

cerdo matar.IM

matan un cerdo,

224) krò tèke,

gallina matar.IM

matan una gallina,

225) sũlĩ tèke;

venado matar.IM

matan un venado;

226) wö̀ mãnẽ̀wẽke sö.

intercambiar.IM 1P.ERG

intercambiamos (estas cosas).

227) E’tã e' wákpala míkenẽ se' tã, se' wé̈tsë PROG DEM dueño.PL.DIM ir.IM.RE $1 \mathrm{P}$ COM $1 \mathrm{P}$ COM Entonces los dueños (espíritus de esos animales) van con uno, con uno,

228) /se' tsốtchök.

1P defender.INF

para defendernos.

229) E' tsé $\mathrm{e}^{\prime}$ mếat Sibö tö se' iã èkkëpë

DEM canto.DET DEM dejar.PER Sibö ERG 1P DAT COMP El canto de eso Sibö nos lo dejó así, 
230) ès Sibö tö i mếat.

así Sibö ERG 3S dejar.PER

así lo dejó Sibö .

Párrafo 29

231) E'kũếk cha ñõlõ̀ diố kĩ se' mĩ̀chò,

CCNS PROG camino DEM LOC 1P irse.IM

Por eso cuando uno se va por aquel camino,

232) e' kî́kã pë' tso' tãì);

DEM encima gente EST mucho

en él hay mucha gente;

233) ye' i kie guárdiapa.

1S 3P llamar.IM guardia.PL

yo los llamo "guardias".

234) Se' dàmĩ tsídalala,

1P pasar. IM pequeño.DIM

La persona va pasando pequeñita,

235) se' duwö̀ã këtchikela,

1P morir.IM mayor.DIM,

(cuando) uno muere mayorcito,

236) wếs ye' ar i'es,

como 1P AP esto.COMP

así como estoy yo,

237) e' wíköl dàmĩ tsídalala,

DEM espíritu pasar.IM pequeño.DIM

su espíritu pasa pequeñito,

238) i chàke:

3S preguntar.IM

y le preguntan:

239) 'Be' dàmĩ̀tche?

2S irse.IM.ING

"¿Ya va yéndose? 
240) A ditsö, a, wế be' yàbolo?"

VOC semilla VOC dónde $2 \mathrm{~S}$ "identificación espiritual"

Oiga, semilla, oiga, ¿dónde (está) su identificación espiritual?

241) E'tã tsố ye' ã,

PROG escuchar.IMP $1 \mathrm{~S}$ DAT

Escúcheme,

242) këkëpa i pàke

mayor.PL $3 \mathrm{~S} \quad$ contar.IM

cuentan los mayores

243) wẽ́ $\mathrm{s}$ a' tsítsipa yékkuö sũwẽ̀ke,

como 2P pequeño.PL libro ver.IM

que así como ustedes, de niños, ven un libro,

244) sũwẽ̀ cha rrèè:

ver.IM PROG fijamente

(ellos) ven (la identificación) fijamente:

245) "Yè̀nẽ je',

cierto AFIR

"Es cierto,

246) sẽ̀nẽ je' ditsö̀ katà kĩ.

vivir.PEAFIR semilla sostén LOC

vivió en el mundo de la semilla.

247) yúshka cha aìñ, i\$:

ir.IMP PROG allá-arriba LOC

Vaya, pues, allá arriba, a:

nẽtabà nẽgolià"

248) E'tã wĩ̀ i mĩ̀ tsẽ:

PROG DEM 3S ir.IM

Entonces si se va allá por:

këëkë cha

rrëkëö rrëkëö

249) 'E' kè rö cha be' ñõlõ̀:

DEM NEG COP PROG $2 \mathrm{~S}$ camino

Ese no es tu camino:

nẽtabà nẽgolià." 
250) Se' dàmĩ,

1P pasar.IM

Uno va pasando,

251) kè yì se' tsirìwẽ;

NEG quien 1P molestar.IM

nadie lo molesta;

252) se’ dàmĩ,

$1 \mathrm{P}$ pasar.IM

uno va pasando,

253) se' sếr $\quad$ kố $\quad$ i' $\quad$ kĩ $\quad$ sulùë,

$1 \mathrm{P}$ vivir.IM lugar DEM LOC mal.INT

si uno vive muy mal en este mundo,

254) se' tchébölö ñì̃ë,

$1 \mathrm{P}$ tacaño siempre

si uno (era) tacaño,

255) $\mathrm{se}^{\prime}$ i $\quad$ wámbale ñ̃ $\quad$ se' wếswẽ sulùë,

$1 \mathrm{P}$ 3S hacer.IM REC 1P algo malo.INT

si uno le hacía cosas malas a la gente,

256) bi chöràa;

2S perder.F/P

perderá;

257) e' kë̀ mĩ̀pa bua'ë.

DEM NEG ir.F/P bien.INT

a ese no le va a ir muy bien.

258) Ìke, be' ếnã i ờnẽ?

INTJ 2S EXP 3S caer.PE

Ea, ¿entiendes?

Escena 6: Otras ceremonias

Párrafo 30

259) Mì̀kã se’ íyi tsố tãwẽ,

TPO 1P cosa primero comprar.IM

Cuando uno (está en edad de) comprar cosas por primera vez, 
260) e'tã se' chöràla,

PROG 1P perderse.IM.DIM

y se muere,

261) e'tã e' ulàwẽ̀kènẽ kékëpa tö;

PROG DEM ceremoniar.IM mayor.PL ERG

entonces los mayores le hacen la ceremonia;

262) e' kie kolò.

DEM llamarse.IM kolò

esa se llama "kolò".

Párrafo 31

263) Ñẽ tté tso' ètökicha,

DEM palabra.DET EST uno

De esos cantos hay uno

264) mî̀chò siáköl,

ir.IM siáköl

(que) es "siáköl”,

265) ètökicha mî̀chò sulàr kéli.

uno ir.IM sulàr kéli

otro que es "sulàr kéli".

266) Sulàr kéli e' rö

sulàr kéli DEM COP

El "sulàr kéli" es para

267) /wếs ye' mẽrkĩ i'es pë' kêkë, como $1 \mathrm{~S}$ AP DEM.COMP persona mayor

una persona que está mayor, como yo,

268) kố tãì,

tiempo mucho

(que tiene) mucho tiempo (de vivir),

269) íyi ulìnẽ tốule bák

cosa todo comprar.ANT. EST.PE

que ya ha comprado todas sus cosas

270) ẽnã ie' wã íyi ulìtãnẽ chẽ̀r,

y $3 \mathrm{~S}$ AG cosa todo saber.IM

y sabe todas las cosas, 
271)

$\begin{array}{lrrr}\text { e'se } & \text { kie } & \text { soló } & \text { kéli. } \\ \text { DEM.COMP } & \text { llamarse.IM } & \text { soló } & \text { kéli } \\ \text { uno como ese } & \text { se llama "soló kéli’. } & \end{array}$

Párrafo 32

272) E’tã kolò e' rö

PROG kolò DEM COP

Entonces el "kolò" es para

273) /mî̀kã se' íyi tsố tãwềmĩ ès, TPO 1P cosa primero comprar.INC así cuando uno empieza a comprar cosas por primera vez,

274) e'tã e'se iã,

PROG DEM.COMP DAT

entonces (es) para uno como ese,

275) chèke kếkëpa tö:

decir.IM mayor.PL ERG

dicen los mayores:

kërë ika wikala ìkãnẽ keie tö, ööö

këböt keae këiã keae keae

276)

$\begin{array}{lllll}\text { Mấmãla } & \text { e' } & \text { che } & \text { i } & \text { di } \\ \text { juguete.DIM } & \text { DEM } & \text { decir.IM } & \text { 3P } & \text { ERG }\end{array}$

Sus cositas, dicen ellos,

277) e' $\quad$ rö $\quad$ kố $\quad$ i'la $\quad$ tsố $\quad$ tãwềmĩ;

DEM COP lugar DEM.DIM primero comprar.INC esto es, (cuando) empieza a comprar su primera tierrita;

278)

e'se sulàwềke wồbala wa.

DEM.COMP ceremoniar.IM ojo con

a esos se les hace la ceremonia con cuidado.

Párrafo 33

279) Pë’ i kãnẽ̀ ũ̀kã ès, gente 3S trabajo hacer.IM así

La gente hacía su trabajo así, 
280) e' rö tsökölpa kãnè̀.

DEM COP cantor.PL trabajo

ese es el trabajo de los cantores.

\section{Abreviaturas}

1P pronombre de primera persona plural

1PE pronombre de primera p. plural exclusiva

1S pronombre de primera persona singular

2P pronombre de segunda persona plural

2S pronombre de segunda persona singular

3P pronombre de tercera persona plural

3S pronombre de tercera persona singular

AFIR partícula afirmativa

AG posposición de agentivo

ANT sufijo de antepresente

AP auxiliar de posición

CCNS conjunción de consecuencia

COM posposición de comitativo

COMP sufijo comparativo

COP cópula

DAT sufijo de dativo

DET sustantivo determinado

DEM pronombre demostrativo

DIM sufijo diminutivo

DIR sufijo direccional

ERG posposición de ergativo

EST verbo estativo 
EXP posposición de experiente

FIN flexión de finalidad

F/P sufijo de futuro / potencial

HORT flexión de hortativo

IDEOF ideófono

IM flexión de imperfectivo

INC sufijo incoativo

INF infinitivo

ING sufijo ingresivo

IMP flexión de imperativo

INT sufijo intensificador

INTJ interjección

INST posposición de instrumental

LOC posposición de locativo

NEG partícula negativa

PE flexión de perfectivo (remoto)

PER flexión de perfectivo reciente

PL sufijo plural

PROG progresión

RE sufijo regresivo

REC pronombre recíproco

REF pronombre reflexivo

RIM elemento rímico

TPO elemento temporal

VOC vocativo

VOL flexión de volitivo 
